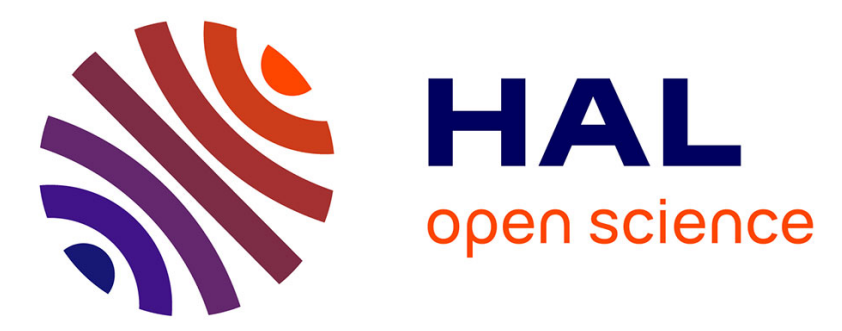

\title{
Les conciles mis en textes, ou comment le Saint-Esprit écrit droit avec des lignes courbes \\ Martin Morard
}

\section{To cite this version:}

Martin Morard. Les conciles mis en textes, ou comment le Saint-Esprit écrit droit avec des lignes courbes. Guillaume Cuchet; Charles Mériaux. La dramatique conciliaire de l'Antiquité à Vatican II, Les Presses universitaires du Septentrion, pp.23-50, 2021, Histoire et civilisations, 978-2-7574-2816-0. hal-03349040

\section{HAL Id: hal-03349040 \\ https://hal.science/hal-03349040}

Submitted on 20 Sep 2021

HAL is a multi-disciplinary open access archive for the deposit and dissemination of scientific research documents, whether they are published or not. The documents may come from teaching and research institutions in France or abroad, or from public or private research centers.
L'archive ouverte pluridisciplinaire HAL, est destinée au dépôt et à la diffusion de documents scientifiques de niveau recherche, publiés ou non, émanant des établissements d'enseignement et de recherche français ou étrangers, des laboratoires publics ou privés. 


\section{Guillaume Cuchet}

Charles Mériaux

(dir.)

\section{La dramatique conciliaire \\ de l'Antiquité à Vatican II}

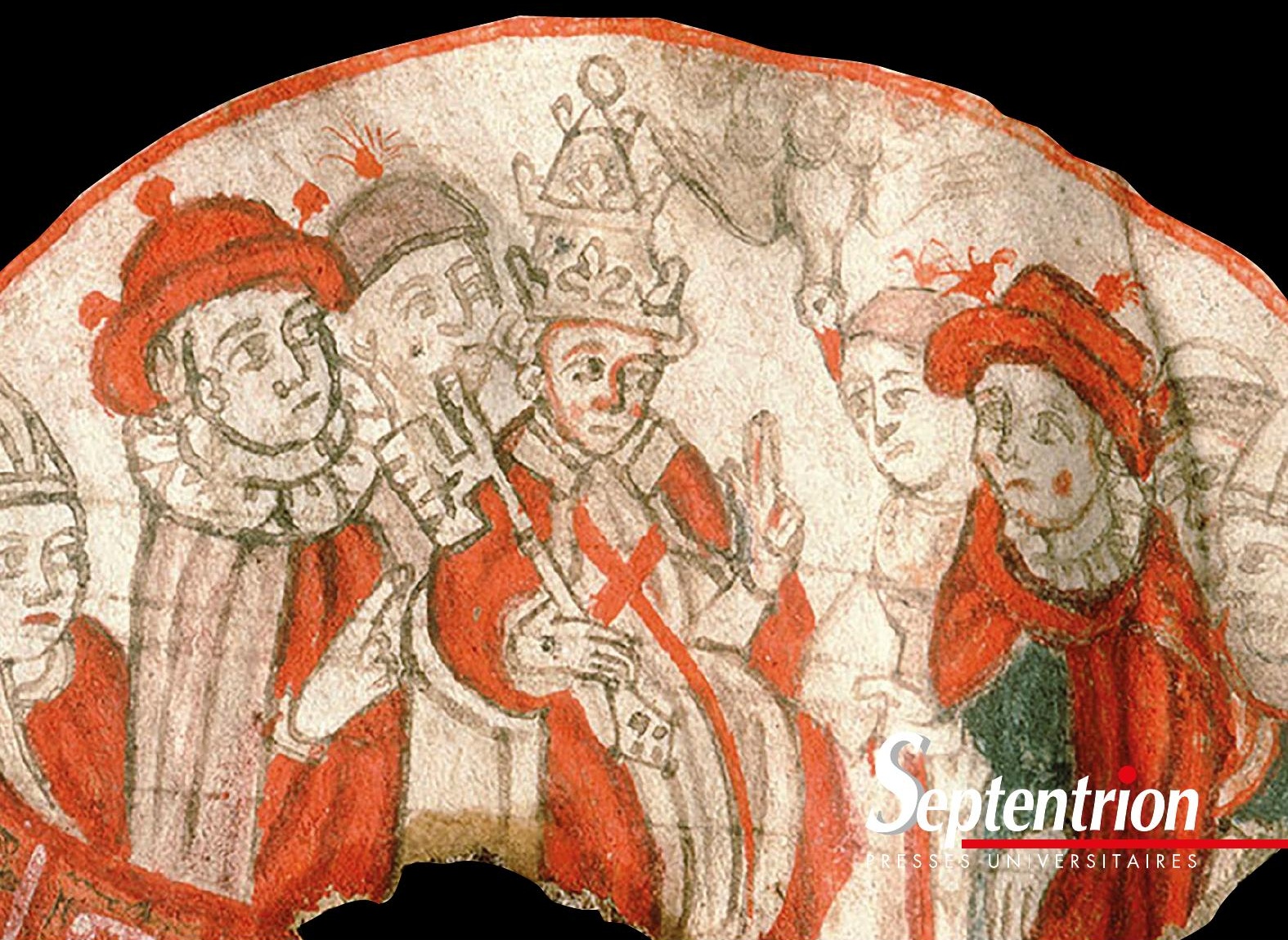




\section{La collection \\ Histoire et civilisations \\ est dirigée par \\ Carole Christen}

Cet ouvrage est publié après l'expertise éditoriale du comité

Temps, espace et société

et d'une double expertise externe.

Le comité est composé de :

- Frédéric Attal, Université Polytechnique des Hauts-de-France

- Xavier Boniface, Université de Picardie - Jules Verne

- Carole Christen (coordinatrice), Université de Lille

- Jean-François Condette, Université d'Artois et ESPE-Lille-Nord-de-France

- Thomas Golsenne, Université de Lille

- Jean Heuclin, Université Catholique de Lille

- Sandrine Huber, Université de Lille

- Yves Junot, Université Polytechnique des Hauts-de-France

- Hervé Leuwers, Université de Lille

- Judith Rainhorn, Université Paris 1 Panthéon-Sorbonne

-Éric Roulet, Université du Littoral - Côte d'Opale

- Emmanuelle Santinelli, Université Polytechnique des Hauts-de-France

- Arnaud Timbert, Université de Picardie - Jules Verne

- Béatrice Touchelay, Université de Lille

- Jérôme Vaillant, Université de Lille 


\section{Les Presses universitaires du Septentrion}

sont une association de cinq universités :

- Université de Lille,

- Université du Littoral - Côte d'Opale,

- Université Polytechnique Hauts-de-France,

- Université Catholique de Lille,

- Université Picardie Jules-Verne.

La politique éditoriale est conçue dans les comités éditoriaux.

Cinq comités et la collection « Les savoirs mieux de Septentrion » couvrent les grands champs disciplinaires suivants :

- Acquisition et Transmission des Savoirs,

- Arts et Littératures,

- Savoirs et Systèmes de Pensée,

- Sciences Sociales,

- Temps, Espace et Société.

Publié avec le soutien de la Communauté d'universités et d'établissements Lille Nord de France et de la Région Hauts-de-France.

(C) Presses universitaires du Septentrion, 2019 www.septentrion.com Villeneuve d'Ascq - France

\footnotetext{
Toute reproduction ou représentation, intégrale ou partielle, par quelque procédé que ce soit, de la présente publication, faite sans l'autorisation de l'éditeur est illicite (article L. 122-4 du Code de la propriété intellectuelle) et constitue une contrefaçon. L'autorisation d'effectuer des reproductions par reprographie doit être obtenue auprès du Centre Français d'Exploitation du Droit de Copie (CFC) 20 rue des Grands-Augustins à Paris.
} 


\section{Guillaume Cuchet, Charles Mériaux (dir.) avec les contributions de}

Silvia Acerbi, Antoine Arjakovsky, Philippe Blaudeau, Séverine Blenner-Michel,

Florence Close, Guillaume Cuchet, Davide Dainese, Thomas Deswarte,

Pierre Antoine Fabre, Loïc Figoureux, Étienne Fouilloux, Étienne Lock,

Catherine Masson, Sylvain Milbach, Hélène Millet, Nelson H. Minnich, Pascal Montaubin,

Martin Morard, Jacques Prévotat, François-Xavier Romanacce, Émilie Rosenblieh,

Philippe Roy-Lysencourt, Christian Sorrel, Ramón Teja, Sophie Vallery-Radot

\section{La dramatique conciliaire de l'Antiquité à Vatican II}

Publié avec le soutien de

I'Institut de Recherches Historiques du Septentrion (UMR 8529 - CNRS)

et de l'Institut universitaire de France 


\section{Politique de diffusion des livres numériques aux Presses universitaires du Septentrion}

Les Presses Universitaires du Septentrion mettent à la vente les livres numériques sur leur site internet sans appliquer de DRM (Digital Rights Management), ceci afin de ne pas réduire les usages de ses lecteurs. Leurs livres numériques n'en restent pas moins soumis au droit d'auteur.

En conséquence, les Presses universitaires du Septentrion demandent à leurs lecteurs de ne pas diffuser leurs livres numériques sur des plates-formes de partage ni de procéder à de multiples copies privées ( $>5$ ).

La violation des droits d'auteurs est constitutive du délit de contrefaçon puni d'une peine de 300000 euros d'amende et de 3 ans d'emprisonnement (CPI, art. L. 335-2 s.).

Le code de la propriété intellectuelle entend par contrefaçon tous les actes d'utilisation non autorisée de l'œuvre.

La loi incrimine au titre du délit de contrefaçon :

- " toute reproduction, représentation ou diffusion, par quelque moyen que ce soit, d'une œuvre de l'esprit en violation des droits de l'auteur, tels qu'ils sont définis et réglementés par la loi » (CPI, art. L. 335-3).

- "le débit [acte de diffusion, notamment par vente, de marchandises contrefaisantes], l'exportation et l'importation des ouvrages "contrefaisants" » (CPI, art. L. 335.2 al. 3). Source : http://www.culture.gouv.fr/Media/Thematiques/ Propriete-litteraire-et-artistique.

Pour plus d'informations, consultez le site internet des Presses Universitaires du Septentrion www.septentrion.com. 


\section{Table des matières}

Introduction

Guillaume Cuchet

\section{PremiÈRE PARTIE \\ ÉCRIRE ET RÉÉCRIRE LA DRAMATIQUE CONCILIAIRE}

Les conciles mis en textes,

ou comment le Saint-Esprit écrit droit avec des lignes courbes

Martin Morard

Nicée (325), ou l'invention de l'hérésie arienne 51

François-Xavier Romanacce

Éphèse I (431) et Éphèse II (449) : concilia ou latrocinia? .75

Ramón Teja, Silvia Acerbi

La réception spirituelle, mémorielle et historique du concile de Florence (1439).

Antoine Arjakovsky

Le problème de l'image dans le dernier acte du Concile de Trente : documents inédits du mois de novembre 1563

Pierre Antoine Fabre

\section{DEUXIÈME PARTIE}

LE PAPE ET LA PAPAUTÉ AU CCEUR DE LA DRAMATIQUE CONCILIAIRE

Sanctionner le pape sans rompre avec le Siège apostolique?

Retour sur la condamnation de Vigile prononcée

lors du concile de Constantinople II (553)

Philippe Blaudeau

Les conciles de la monarchie pontificale (1049-1312) :

des conciles sans drame?

Pascal Montaubin 
La condamnation de deux papes fauteurs

de schisme : un drame conciliaire (Pise, 1409)

\section{Hélène Millet}

La dramatique conciliaire à Constance (1414-1418) :

la fuite de Jean XXIII du concile.

\section{Sophie Vallery-Radot}

Le Saint-Esprit ou la légitimation de l'autorité conciliaire :

le procès du pape Eugène IV au concile de Bâle (1431-1439)

\section{Émilie Rosenblieh}

Dramatique inopportune : le concile du Vatican et l'opinion dans les pas de Mgr Dupanloup et de Louis Veuillot

Sylvain Milbach

\section{TROISIÈME PARTIE \\ L'EMPEREUR, LE ROI, L'ÉTAT, ACTEURS DE LA DRAMATIQUE CONCILIAIRE}

Le rôle de Constantin au concile de Nicée selon Eusèbe de Césarée. 259

\section{Davide Dainese}

Tolède III (589) et Tolède IV (633) :

deux conciles, deux conceptions du pouvoir

\section{Thomas Deswarte}

Le synode ecclésiastique de Francfort (794):

un concile carolingien bien inspiré ?

\section{Florence Close}

La résolution des conflits

entre la France et le Saint-Siège au Ve concile du Latran (1512-1517) 311

Nelson H. Minnich

Le Saint-Esprit corrigé ?

Le Saint-Siège face au concile provincial de Paris (1849-1850).

\section{Séverine Blenner-Michel}

$$
\begin{gathered}
\text { QuatRIÈme PARTIE } \\
\text { LA DRAMATIQUE PAR EXCELLENCE : } \\
\text { VATICAN II, LES MOMENTS, LES HOMMES, LES GROUPES }
\end{gathered}
$$

La « semaine noire » de Vatican II

\section{Étienne Fouilloux}

Henri de Lubac, un homme aux « ailes de géant » au concile Vatican II. 
L'intervention du cardinal Liénart au concile Vatican II le 13 octobre 1962....... 385

\section{Catherine Masson}

La Panafricaine épiscopale au Concile Vatican II :

simple tactique ou souci de représentativité ? 405

Étienne Lock

Les traditionalistes du Coetus Internationalis Patrum

dans la dramatique du concile Vatican II

Philippe Roy-Lysencourt

Événement et conscience de l'événement dans le journal du concile Vatican II du sulpicien Marcel Breysse 441

Christian Sorrel

Conclusion

Jacques Prévotat 


\title{
Les conciles mis en textes, ou comment le Saint- Esprit écrit droit avec des lignes courbes
}

\author{
Martin Morard \\ CNRS, Institut de recherche et d'histoire des textes, Paris
}

\begin{abstract}
La VRAie INTELLIGenCE (DE la foi) vient de l'Écriture par les conciles », disait (Thomas d'Aquin'. Mais l'intelligence des conciles ne suit pas des chemins rectilignes : elle passe par les méandres d'une documentation foisonnante ; elle exige la connaissance des arguments exposés au cours des délibérations. Le dogme ne livre son sens qu'à travers son histoire. Les six premiers conciles œcuméniques, communs à l'Orient et à l'Occident ${ }^{2}$, événements fondateurs de l'architecture doctrinale du christianisme, peuvent être envisagés comme un drame en plusieurs actes, mis en scène par leurs acteurs historiques. La construction de leur mémoire dépend de la « mise en textes » de leurs sessions, que les latins ont appelée gesta ou actiones, moins pour traduire le $\delta p \tilde{a} \mu \alpha$ de l'action théâtrale, que le $\pi p \tilde{\alpha} \xi ı$ ls le l'agir et de son résultat. II n'en demeure pas moins que la fabrique des documents conciliaires fait partir intégrante de la dramatique conciliaire. L'histoire des collections d'actes des premiers conciles est en effet révélatrice des contingences qui grèvent la transmission des témoins matériels de la tradition de la foi. C'est notamment sur ces documents fragiles, parfois sortis de leur contexte et mal compris, que reposent les cathédrales de la christologie médiévale.
\end{abstract}

1 Thomas d'Aquin, Contra errores Græecorum 1, 32 : Verus intellectus ex Scriptura per concilium. - Je remercie Fabio Gibiino qui m'a aidé à rendre ce travail moins imparfait par sa relecture et ses suggestions.

2 Pour Byzance, l'œcuménicité, garante d'une représentation universelle, est le fait de la convocation de l'empereur, maître de l'oikuménè. Pour Rome, l'œecuménicité dépend de la convocation et de la confirmation pontificale et a pour conséquence une autorité doctrinale universelle et solennelle ; cf. R. DevREESSE, « Le cinquième concile et l'œecuménicité byzantine », Miscellanea Giovanni Mercati, t. III, Cité du Vatican, coll. «Studi e testi », 123, 1946, p. 1-15 et, plus loin, n. 12. 
Les premiers conciles ont tous été célébrés en langue grecque, sur le territoire de l'empire byzantin, par des évêques en majorité non latins ${ }^{3}$. On en connaît les décisions disciplinaires et dogmatiques, rassemblées dans des collections canoniques aujourd'hui abondamment étudiées ${ }^{4}$. Mais comment les procès-verbaux des débats proprement dits sont-ils parvenus au monde occidental ? Comment celui-ci les a-t-il reçus ? Le terrain a été largement balisé par l'édition des Acta conciliorum œcumenicorum, commencée en 1926 par Edouard Schwartz (†1940) et poursuivie jusqu'à nos jours ${ }^{5}$. Ce travail monumental, munis d'index exemplaires ${ }^{6}$, remplace les éditions de Mansi et Labbé mais demeure sous-exploité en raison de la grande complexité des matériaux traités. Schwartz a été un des premiers à prendre en compte en ce domaine la notion de collection comme source historique. Les quinze volumes in quarto de la première série totalisent près de 6 ooo pages d'éditions et 1751 pages d'index. Les préfaces disséminées au fil de la publication, rédigées d'abord en latin, puis en allemand, sont rarement lues et encore moins assimilées. Elles appellent une synthèse qui tienne compte des évolutions historiographiques et des nombreuses retractationes des éditeurs au fil d'un travail éditorial de 90 ans?

Je me contenterai ici de quelques remarques destinées à rappeler d'abord comment les collections conciliaires sont tributaires du contexte polémique des conciles et de la forme des débats synodaux. Puis, je tenterai un essai de typologie des collections et un parcours cavalier de leur histoire. Le cas exemplaire du Synodicon de Rusticus lu par

3 Voir Annexe 1.

4 Pour une vue d'ensemble pratique et documentée, cf. L. Fowler-MagerL, Clavis canonum. Selected canon law collections before 1140. Access with data processing, Hanovre, coll. « MGH. Hilfsmittel », 21, 2005.

5 Acta conciliorum œecumenicorum, abrégés désormais sous la forme ACO. Les actes de Nicée II (787), nœud de la querelle iconoclaste, ne sont parus qu'en 2008 dans la même collection (ed. E. LAmBERz). Thomas d'Aquin ne les cite que par l'intermédiaire du Décret de Gratien. Cf. Quodlibet 9 q. 7 a. 2 arg. 2, ed. Leonina, t. 25/1, p. 116.17-21, d'après Grat., 21, 1, 1 (Friedberg. 852).

6 Cf. R. SchIEFFER, Acta conciliorum oecumenicorum. Index generalis tomorum I-IV, Indices codicum et auctorum, Berlin, 1974 (ACO 4/3/1).

7 Pour une critique récente de Schwartz, voir les études rassemblées dans Crux interpretum : Ein kritischer Rückblick auf das Werk von Eduard Schwartz, dir. U. HEIL, A. vON STOCKHAUSEN, Berlin/Boston, 2015. R. SchIEFFER, Gesammelte Schriften, t. IV, Berlin, 1960, p. 329-344 avait déjà proposé une analyse des études de Schwartz sur l'histoire des conciles. P. Peeters, dans Analecta Bolladiana, t. 54, 1936, p. 143-159 s'élève contre Schwartz qui a trop déprécié Rusticus. Pour la période post-chalcédonienne et les synodes de 519, 536 et 553, cf. R. SCHIEFFER, ACO, 4/3/1, p. 518-520. - Sur la problématique des collections tardo-antiques et médiévales, voir L'Antiquité tardive dans les collections médiévales. Textes et représentations (Vle-XIVe siècle), dir. St. Gioanni et B. Grevin, Rome, 2008. 
Thomas d'Aquin aidera à comprendre comment l'histoire documentaire a pu influencer jusqu'à la réception de l'enseignement dogmatique des premiers conciles au Moyen Âge ${ }^{8}$. Thomas est en effet le premier théologien occidental latin à avoir appuyé son argumentation sur une connaissance de première main des actes - et non seulement des canons - des conciles d'Éphèse, Chalcédoine, Constantinople II et III, non sans quelque maladresse dont nous voudrions rendre compte.

\section{- Contexte historique et enjeux doctrinaux}

L'histoire des six premiers conciles et de leurs actes écrits est marquée par le contexte hautement polémique de l'élaboration du dogme trinitaire et christologique. L'Église des premiers siècles chercha d'abord à obtenir un consensus sur l'interprétation d'expressions problématiques du Nouveau Testament concernant l'être de Dieu (la Trinité) et celui du Christ (l'union hypostatique). Les discussions - qui tournèrent parfois au pugilat - portaient sur la façon dont il convenait d'appliquer au cas unique de Jésus-Christ, vrai Dieu et vrai homme, des termes grecs

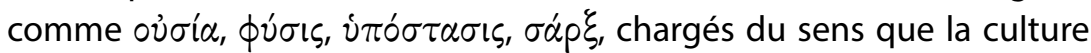
profane leur conférait mais également réhabités par la foi. II s'agissait d'en définir la portée de manière à ce qu'ils puissent permettre à tous, au-delà des frontières politiques, linguistiques et culturelles, de rejoindre une réalité sans équivalent dans l'expérience humaine : l'être du Christ, Verbe incarné, connu par le seul donné scripturaire, composé de textes hétérogènes, écrits dans un langage qui semblait de plus en plus équivoque, au vu des interprétations antagonistes qu'il suscitait. Il a donc fallu faire évoluer le sens des mots pour qu'ils puissent se rejoindre dans une analogie de consensus : $\sigma \alpha ́ p \xi$ désignera la totalité de l'être

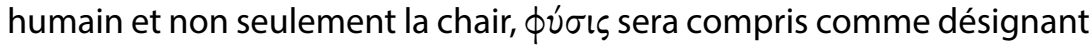
la nature et non pas l'être subsistant au sens de personne, traduit plutôt par $\pi \rho o ́ \sigma \omega \pi \circ \nu$; ov̉ $\sigma^{\prime} \alpha$ désignera la substance et non pas la nature. Entre le canon des textes scripturaires désormais arrêté et le langage de la vie " courante » du bassin méditerranéen, les conciles, sénats de l'Église, eurent à construire un espace sémantique stabilisé, capable de fonder

8 La présente contribution prolonge deux études qui portaient sur la connaissance que Thomas d'Aquin avait eue des collections anciennes d'actes conciliaires. II s'agissait alors de mesurer l'influence des conciles sur son exégèse biblique et sa christologie. Cf. M. MORARD, "Une source de saint Thomas d'Aquin : le deuxième concile de Constantinople (553) », Revue des sciences philosophiques et théologiques, t. 81, 1997, p. 21-56; ID., " Thomas d'Aquin lecteur des conciles », dans «Ad un fine fur l'opere sue ». Miscellanea di studi per commemorare i trent'anni di permanenza della Commissione Leonina (OP) nel Collegio di S. Bonaventura (OFM) di Grottaferrata (1973-2003), Archivum franciscanum historicum, t. 98, 2005, p. 211-365. 
la cohésion des croyants. Unité socio-politique et unité des Églises reposent sur la foi en l'unité de l'être du Christ qui ne peut être comprise que par la médiation d'une sorte de koinè dans la koinè, élaborée par les conciles. Cependant les protagonistes et ce qu'ils représentent s'affrontent au sein d'un espace géo-politique qui s'étend entre quatre pôles d'influences - Antioche, Alexandrie, Constantinople et Rome entre lesquels les tensions doctrinales sont accentuées par le désaccord au sujet de la préséance des sièges patriarcaux. À cette époque, le rôle

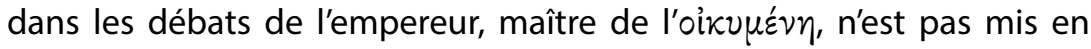
cause, mais la question de savoir si la primauté ecclésiastique se définit en fonction de l'antiquité du siège apostolique, comme l'affirme Rome, ou de sa proximité avec le pouvoir politique, comme le revendique Constantinople, va mettre en échec l'unité ecclésiale que les conciles avaient presque réussi à préserver autour du dogme. L'Europe occidentale chrétienne développera ses racines sur la ruine de ce premier édifice méditerranéen fondé sur l'exercice chaotique de la synodalité.

Nicée définit donc d'abord contre Arius la divinité du Christ

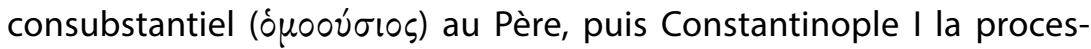
sion du Saint-Esprit du Père par le Fils, posant ainsi les fondements du dogme de la Trinité des personnes dans l'unité de la substance divine. Deux systèmes christologiques se sont alors affrontés pour rendre raison du fait de l'Incarnation en accord avec la foi de Nicée. L'un antiochien, auquel se rattachaient plutôt Rome et l'Occident, mettait en valeur la distinction des natures et insistait sur le réalisme de l'incarnation et de l'humanité du Christ, au risque, - chez Nestorius - de nuire à l'unité de la personne du Christ et d'estomper la gloire de sa divinité. L'autre, alexandrin, avec Cyrille d'Alexandrie pour champion, soulignait l'unité de l'être du Christ, au risque du monophysisme. En définissant le dogme des deux natures du Christ, unies sans mélange ni confusion dans l'unité d'une seule personne, sans division ni séparation, Chalcédoine, grâce à la théologie de Léon le Grand, imposait un équilibre entre les tendances dualistes des Nestoriens et monistes du parti de Cyrille. Enfin, Constantinople III, préparé par le concile romain de 649, proclama l'existence de deux volontés et de deux opérations dans le Christ, condamnant l'erreur contraire du monothélisme, soutenue par Gaianus et Macaire d'Antioche. Mais un siècle plus tôt, les querelles de partis mettaient à mal le difficile équilibre que Chalcédoine avait réussi à préserver entre condamnations des doctrines et respect de leurs auteurs. Les partisans de Cyrille avaient provoqué la convocation de Constantinople II par un certain nombre de fausses allégations 
et d'interprétations tendancieuses. Connu sous le nom d'affaire des Trois Chapitres, il précisa la christologie chalcédonienne en condamnant certains modèles explicatifs dualistes de l'Incarnation, tels celui de l'assumptus homo, portés par les écrits de Théodore de Mopsueste, Théodoret de Cyr et lbas d'Édesse. L'opposition du pape à la convocation du concile et à cette condamnation tardive d'évêques morts dans la communion de l'Église malgré des écrits fautifs, conduisit à son excommunication au cours de la septième session. Justinien, par décret, déclara Vigile hérétique ${ }^{9}$. En raison de cette rupture, d'un point de vue romain, les décisions du 2 juin ( $8^{e}$ session) ne revêtent l'autorité propre à un concile œcuménique que dans la mesure exacte où Vigile les a intégrées à deux documents postérieurs : une lettre adressée au concile par l'intermédiaire d'Eutychès, patriarche de Constantinople (Epistula "Scandala », 8 décembre 553) et surtout le décret du 23 février 554 (Constitutum II) par lequel il se ralliait au concile et à la condamnation des thèses non conformes à la doctrine chalcédonienne, mais non à la condamnation des personnes de Théodore, Théodoret et lbas ${ }^{10}$. Par-dessus tout il établissait l'autorité inviolable de Chalcédoine. Ce document ne souffle mot des canons christologiques". Cependant, la troisième lettre de Cyrille à Nestorius et ses douze anathématismes n'avait jamais reçu à Chalcédoine la valeur de définition conciliaire que les pères de Constantinople II lui attribuèrent à tort. Par conséquent, Vigile ne l'a pas approuvée non plus avec le reste des actes de Constantinople II. Certains ont donc pensé que, en rigueur de terme, les anathématismes de Cyrille n'avaient pas la portée définitive, universelle et solennelle qui qualifie les décisions des conciles œcuméniques ${ }^{12}$. En fait, la réconciliation scellée par le Constitutum II

$9 \mathrm{ACO}, 4 / 1, \mathrm{p} .20 \mathrm{O}_{37}-201_{8}$ etc.

$10 \mathrm{ACO}, 4 / 2$, p. $138_{2}-168_{30}$

11 Les volte-face pontificales provoquèrent l'opposition d'une partie du clergé latin, entraînant de graves troubles en Afrique et en Italie. Paulin, évêque d'Aquilée, fit rejeter la condamnation des Trois Chapitres dès 553 par un concile provincial, inaugurant un schisme qui durera jusqu'au début du VIII' siècle. ACO, 2/6, p. XIII-XIV : Cum propter controversiam de tribus capitulis in occidente concilii Chalcedonensis memoria acriore studio revivisceret pullularentque gestorum epistularumque quae ad illud pertinebant, versiones, etiam encyclicorum corpus in maiorem concilii gloriam a (...) Epiphanio in latinum sermonem converti curavit Cassiodorus senator, quando Gothorum regno destructo, de vita publica secessit atque in Vivario ampla bibliotheca congesta clericae iuventuti instituendae operam dedit.

12 Voir plus haut, n. 2 et Ch. Moeller, "Le cinquième concile œcuménique et le magistère ordinaire au Vle siècle », Revue des sciences philosophiques et théologiques, t. 34, 1951, p. 413-423, ici p. 413-414. Le Constitutum / du 14 mai 553 avait été déclaré irréformable par Vigile lui-même: His igitur competenter et per orthodoxae fidei rectitudinem apostolicae sententiae auctoritate damnatis constituimus, ut ex omnibus istis quae nos, patrum statutis 
impliquait une confirmation tacite de l'ensemble ; seuls les points litigieux étaient précisés. Ce n'était pas la doctrine christologique définie à Éphèse et Chalcédoine qui avait été remise en cause, mais la condamnation personnelle de Théodore, Ibas et Théodoret. Constantinople II a donc été reconnu en Occident dans l'exacte mesure de sa conformité à la doctrine des conciles antérieurs ${ }^{13}$. Toutefois, cette réserve exprimée par le pape n'a pas suffi à écarter du patrimoine doctrinal de Constantinople II les textes que les partisans de Cyrille y avaient présentés à tort comme définis à Chalcédoine, en les glissant à l'intérieur d'une relecture de ce dernier concile.

\section{- Déroulement des conciles et composition des acta synodalia}

La dramatique des conciles se prolonge donc dans leur mise en texte et jusque dans leur réception. Elle invite à prêter attention au contenu et à l'histoire de la documentation qui les relate. Le contenu des collections conciliaires est d'abord déterminé par le déroulement même des conciles. Un concile œcuménique n'est pas une chambre d'enregistrement, mais une assemblée d'évêques qui cherchent à définir la foi et la discipline commune. L'Église étant devenue un organisme d'empire, ses synodes à portée universelle sont convoqués par l'empereur et présidés par lui, avec l'accord du pape de Rome. Des légats le représentent ainsi que la totalité de l'épiscopat, même si un très grand nombre d'évêques latins sont absents. Les débats portent sur des questions fixées d'entente par l'autorité civile et ecclésiastique. Les représentants de l'empereur

atque traditionibus inhaerentes, apostolica auctoritate damnavimus, nulla iniurandi praecedentes patres (...) praebeatur occasio (Epist. 83, 202, CSEL, 35, p. 286 ${ }_{11-16}$ ). Sa présence au Moyen Âge est bien attestée. II a été édité à partir des manuscrits de la Collectio Avellana, notamment le BAV, Vat. lat. 3787 (fin Xle siècle) en provenance du monastère camaldule de Sainte-Croix de Fontavellane. Mais on ne le trouve plus dans d'autres manuscrits tardifs (p. ex. BAV, Vat. lat. 5617 ; Roma, Angelica, 292 ; cf. CSEL, 35, p. III-xxxxIIII).

13 Y. Congar, «La Primauté des quatre premiers conciles», dans B. Botte, H. MARot, P. Th. CAmelot et al., Le Concile et les conciles. Contribution à I'histoire de la vie conciliaire de l'Église, Paris/ Chevetogne, 1960, p. 75-109, ici p. 109 et B. SEsBoǘ, Jésus-Christ dans la tradition de l'Église, Paris, 1982, p. 156-157. - À partir du VII siècle, l'acceptation notoire de Constantinople II en Occident par des autorités comme Grégoire le Grand ou Gratien est susceptible d'ôter toute hésitation ; cf. GreGorIUS MAGNus, Regist. epist. lib., 50, 140 (CCSL 140, 1982, l, p. xXIV, 32 et 368-381 ; VIII, p. xxXI, 493 et 38-42) ; LATRAN (649), D.-S. n. 501-520 ; Const. III, D.-S. n. 554 ; Grat. 24 , 2, 5-6 (Fr. 986-987) citant les actiones 1, 4, 5 ; cf. aussi 1, 15, 2 (Fr. 35), 1, 16, 9-10 (Fr. 45-46) : Quinta [synodus] in Constantinopolim, contra Theodorum Mosophenum et omnes hereticos; qui Theodorus dicebat alium esse Dei Verbum et alium Christum... ; Gratien paraît ne pas en citer les canons et oublier Théodore dans sa liste des hérésies, ibid., 2, 24, 39 (Fr. 1001-1006). Au tournant du IX siècle, les professions de foi officielles admettaient généralement six conciles œcuméniques; cf. Y. CongAR, op. cit., p. 83-85 et n. 58. 
assurent la présidence civile du concile. Le nombre des sessions va de trois à Éphèse, jusqu'à dix-huit pour Chalcédoine et Constantinople III. Les pères se font d'abord réciter publiquement tout ou partie des délibérations des synodes précédents, au cours desquelles les synodes antérieurs avaient eux-mêmes été lus. Cette traditio doctrinae, quasi rituelle, donne lieu à un effet de " poupées russes ». Certains fragments sont lus plusieurs fois au cours d'un même concile, ainsi que d'autres documents : textes de conciles particuliers, lettres ou manifestes doctrinaux, florilèges de citations, extraits de commentaires bibliques. Tirés des archives ou préparés par les partis, ils sont discutés, puis archivés à leur tour comme éléments des délibérations. Hué ou applaudi, chacun prend la parole à son gré pour avancer son opinion ou proposer une interprétation. Il s'agit de soumettre à l'appréciation des participants une lettre, une proposition qui fait problème en la confrontant à la foi commune. Certains textes font l'objet d'une critique serrée. Interpolations et falsifications n'ont pas manqué, face auxquelles les pères conciliaires eurent parfois de la peine à faire la part de Dieu et de César, quand ce n'est pas celle du diable. On sait comment, à Constantinople III, les légats romains, à qui on voulait opposer des pièces favorables au monothélisme, réussirent à prouver la falsification de l'authentique des actes de

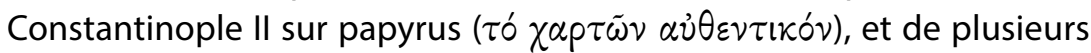
autres exemplaires sur parchemin, en montrant que des cahiers non signés avaient été glissés aux endroits stratégiques des volumes au sein même de la bibliothèque du patriarchat ${ }^{14}$. La traduction latine et l'unique manuscrit qui en reste - dépendent de cet authentique... inauthentique, nous y reviendrons. Il faut donc y regarder à deux fois avant de considérer comme munie de l'approbation conciliaire des pièces répétées et parfois déformées. Certaines citations conciliaires médiévales, notamment chez Thomas d'Aquin, dépendent de ces sources indirectes ${ }^{15}$.

Les décisions arrêtées sont ensuite résumées sous un double mode positif et négatif. D'abord, en quelques dizaines de lignes, une sententia expose et définit la doctrine orthodoxe approuvée par l'assemblée. Les pères entérinent aussi certaines lettres, dites alors " synodiques", dans lesquelles ils reconnaissent l'expression orthodoxe de la doctrine discutée. Approuvées de tous, elles ont valeur de définition conciliaire : ainsi, le «Tome à Flavien » de Léon le Grand à Chalcédoine, la seconde lettre de Cyrille à Nestorius à Éphèse, la lettre du pape Agathon à

14 Pour le détail de cette affaire, cf. R. DeVREESSE, « Le cinquième concile», op. cit., p. 12-14.

15 Nous nous permettons de renvoyer à ce propos aux études citées ici à la note 8. 
Constantinople III. Tel ne fut pas le cas de la troisième lettre de Cyrille à Nestorius, malgré la méprise qu'on a dite plus haut. Des canons doctrinaux ou capitula, assortis d'un anathème conditionnel, expriment ensuite par la contradictoire les positions de foi définies en résumant les positions hétérodoxes combattues sous forme de proposition négative : Si quis... anathema sit. Des canons disciplinaires, reflets du contexte pastoral du moment et sans lien avec les enjeux doctrinaux, peuvent conclure le tout. Constantinople II et III firent exception en ne publiant pas de canon disciplinaire. Après Constantinople III, une session complémentaire fut donc convoquée à cette fin, plus connue sous le nom de concile In Trullo ou Quinisexte tenu à Constantinople en 691/692. Faute de confirmation pontificale, il ne jouit pas des prérogatives de l'œcuménicité ${ }^{16}$. Les médiévaux ont considéré les deux assemblées tantôt comme des conciles distincts, tantôt comme les sessions d'un même concile ${ }^{17}$. Grâce aux collections canoniques ces canons furent plus largement diffusés que les débats conciliaires proprement dits. Néanmoins, d'un point de vue doctrinal, le document central d'un concile est la définition de foi lue en cours de séance, sanctionnée par un vote majoritaire reconnaissant qu'elle concorde avec la foi des conciles antérieurs.

Enfin, les actes sont soumis à l'approbation des autorités impériales et à la confirmation de l'évêque de Rome qui précise éventuellement la mesure de son approbation, comme à Constantinople II. Sous l'autorité du premier notaire, également responsable des archives, les délibérations firent progressivement l'objet des mêmes prises de notes que les assemblées du Sénat, des cours de justice ou du consistoire impérial. Les premiers conciles de Nicée et Constantinople n'avaient pas du tout été mis par écrit. Leurs définitions et canons ne sont connus que par les résumés qu'en font les conciles d'Éphèse et Chalcédoine. Le Symbole de Constantinople I ne subsiste même qu'à partir des citations qu'en fait Chalcédoine, 70 ans plus tard.

16 C. J. Hefele et H. LeCLerCQ, Histoire des conciles, t. III-1, p. 560 ; cf. V. LauRent, «L'œuvre canonique du concile in Trullo (691-692) source primaire du droit de l'Église orientale», Revue des études byzantines, t. 23, 1965, p. 7-41; H. OHME, « Die sogennanten "antirömischen Kanones" des Concilium Quinisextum (692). Vereinheitlichung als Gefahr für die Einheit der Kirche », dans The Council in Trullo revisited, éd. G. Nedugzat et M. Featherstone, Rome, coll. «Kanonika », 6, 1995, p. 307-321. Les grands canonistes grecs du Xlle siècle comme Zonaras ou Balsamon affirmaient même que ce concile n'avait promulgué aucun canon ; cf. lo. Zonarae, ... in canones ss. Apostolorum et sacrorum conciliorum, tam Oecumenicorum quam provincialium commentarii..., Paris, 1618, p. 123b ; PG, 137, 499D et Th. BALSAMON, dans

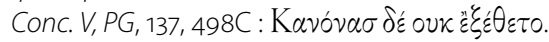

17 Grat. 1, 16, 6, cf. 4 et 5 (Fr. 42-44) : in septima autem sinodo sive in sexto concilio apostolorum canones [sunt] recepti... 
Pendant le concile, les textes d'origine latine, émanant de Rome par exemple, avaient été traduits en grec avant d'être lus. Après la clôture, la mise en collection et la diffusion des actes suit un parcours complexe. Les déformations induites par les sélections et les réécritures qui président à leur élaboration se sont conjuguées avec les relectures plus ou moins biaisées effectuées au cours des sessions et les pertes matérielles sévères subies par les archives. À Éphèse, on se rendit compte de la difficulté posée par le manque d'archives. À partir de Chalcédoine, les procès-verbaux des délibérations deviennent pléthoriques ; ils relèvent jusqu'aux acclamations et applaudissements. Ils commencent par les lettres de convocation et la liste nominative des évêques présents. Les acteurs de la diffusion des collections latines ajoutèrent à la masse déjà considérable des acta synodalia une documentation interconciliaire abondante faite de dossiers patristiques - lettres, sermons et florilèges tantôt à charge, tantôt à décharge, selon l'intention des compilateurs. À Chalcédoine et Constantinople II, les lettres échangées entre les pères avant ou après les débats furent également archivées. Car entre les conciles, les débats ne cessent pas. Les protagonistes écrivent, s'écrivent ou s'insultent, renient les réhabilitations déjà scellées, jusqu'à ce que la convocation d'un nouveau concile tente à son tour d'y mettre bon ordre.

Tout concile est donc une entreprise de collecte orientée, infléchissant l'interprétation des textes par une succession de redites, d'interpolations, d'omissions et de redécoupages opérés non seulement par les pères mais aussi par des acteurs de second ordre qui agissent sans autorité en aval des débats. Les textes sont toujours faillibles. Le sens et la portée d'une pièce isolée ne sont jamais évidents. Une confiance aveugle ne peut être faite ni aux traductions, ni même aux actes dits authentiques, quand ils ont survécu. Les conciles doivent être lus à la lumière les uns des autres au moyen d'une critique serrée de leur histoire textuelle. À l'instar de l'Écriture, ces témoins de la foi ne sont audibles, comme tels, qu'à travers l'écho de leur réception ecclésiale.

\section{- Les collections : essai de typologie}

Aujourd'hui comme hier, les conciles sont le plus souvent connus à travers des recueils qui sont le résultat d'opérations de sélection et de traduction menées au service d'une intention doctrinale, dans un but pratique et dans un contexte ecclésial précis. Les collections des premiers conciles sont toutes le fait d'initiatives privées, parfois encouragées par le pape, parfois entreprises pour s'opposer à lui, en diffusant hors des 
milieux lettrés de Rome une vision particulière des conciles, notamment dans le contexte de la polémique des Trois Chapitres.

Les six premiers conciles ont donné lieu à une vingtaine de collections latines d'actes. Rien n'a été conservé pour Nicée et Constantinople I (la definitio fidei et le symbole - Credo - de ce dernier n'apparaissant pas avant la première session de Chalcédoine), huit collections sont recensées pour Éphèse, quatre pour Chalcédoine, cinq pour Constantinople II, une seule pour Constantinople III et le concile du Latran de 649. La réception problématique de Constantinople II est à l'origine de la plupart des collections latines concernant Éphèse, Chalcédoine et Constantinople II ; un même éditeur-traducteur, Rusticus, intervint dans la traduction des actes d'Éphèse et Chalcédoine d'une part (collectio Casinensis), de Constantinople II d'autre part. À l'exception des conciles anti-monothélistes, les collections latines ne se limitent jamais à un procès-verbal ; elles y ajoutent toujours des collections de lettres, de libelles et des dossiers canoniques et théologiques qui se rapportent peu ou prou aux débats synodaux sans y avoir été nécessairement produits. Aucune collection latine conservée n'a de caractère officiel. Toutes sont issues d'un parti ou liées à une polémique.

La typologie de ces documents est complexe. Les érudits ont eu tendance à " neutraliser » le contexte original des collections en les baptisant du nom du lieu de conservation ou de provenance de leur principal témoin, alors qu'il existe souvent plusieurs manuscrits d'une même collection et qu'un même lieu de conservation peut abriter plusieurs collections. L'histoire contemporaine distingue plutôt les gesta synodalia, procès-verbaux des séances conciliaires ${ }^{18}$, de ce que Schwartz appelait les Publizistischen Sammlungen ${ }^{19}$, c'est-à-dire les recueils de toute nature destinés à la propagande des partis théologiques impliqués. Certains préfèrent parler à leur sujet de florilèges polémiques ${ }^{20}$, les autres d'acta, au risque d'une confusion avec les procès-verbaux des sessions, appelées elles-mêmes acta à Chalcédoine. Nous nous en tiendrons, pour notre part, à la notion de « documentation conciliaire » à

18 Une autre classification distingue Konzilakten et Konzilsprotokollen, cf. G. MAY, "Das Lehrverfahren gegen Eutyches im November des Jahres 448 », Annuarium historiae conciliorum, t. 21, 1989, p. 1-61, ici p. 30-40.

19 P. Peeters dans Analecta Bollandiana, t. 54, 1936, p. 143-159 (ici p. 158) conteste l'expression : «L'idée d'agir sur l'opinion par la simple présentation de pièces authentiques n'a pu prendre une forme aussi définie qu'après l'invention de l'imprimerie ». Peeters préfère parler, non sans raison, de «florilèges polémiques ».

20 A. GRILLmeIER, Le Christ dans la tradition chrétienne, t. II-1, Le concile de Chalcédoine (451) : réception et opposition, Paris, 1990, p. 42 et note précédente. 
dominante tantôt historique ou génétique, tantôt idéologique, tantôt générique ou diplomatique, chacune de ces dimensions étant présente à des degrés divers dans chaque collection.

Les collections de type "génétique » rassemblent des textes principalement en fonction de l'ordre chronologique ${ }^{21}$. On y distingue trois sous-groupes:

1. Les « collections archétypales » correspondent aux « authentiques » grecs des procès-verbaux de sessions établis par les notaires primiciers de la chambre impériale. Ce sont elles qui sont signées par les participants et approuvées par le pape et l'empereur. Certaines ont été falsifiées. Justinien II, qui leur vouait une vénération quasi religieuse, en prit prétexte pour réclamer la convocation du concile in Trullo /l en 691/692. La plupart sont aujourd'hui perdues ou ne subsistent plus qu'en latin.

2. Les collections de deuxième génération contiennent les premières traductions des collections archétypales rassemblées dans un contexte souvent partisan. Elles se limitent rarement aux seuls actes d'un concile. Éphèse et Chalcédoine ont ainsi fait l'objet de plusieurs recensions enrichies de documents annexes, entre lesquelles les différences sont parfois notables, comme le Synodicon de Rusticus ${ }^{22}$ et la Collectio Veronensis des actes d'Éphèse. Très amples, la plupart ont été démembrées, recomposées ou tronquées au fil des copies. Certaines peuvent donc contenir des extraits de plusieurs autres collections, agencés selon un ordre différent d'un exemplaire à l'autre. Seule l'édition des $A C O$ permet de prendre conscience de la complexité de ces recompositions grâce à une vue d'ensemble de leur tradition manuscrite.

3. Les collections de troisième génération sont des recueils d'extraits effectués à partir des collections de seconde génération par des éditeurs tardo-antiques ou médiévaux, en fonction de critères thématiques ou pratiques. L'intention de l'éditeur est guidée par le contenu intellectuel des pièces. La conscience de l'unité historique des versions antérieure semble perdue. Cette génération est, par nature, celle des ajouts et interpolations. Leur texte a souvent fait l'objet de corrections soit grammaticales, soit par confrontation avec un autre manuscrit ou un texte grec. Ainsi, dans la Dionysiana aucta, la première collection canonique due à l'industrie de Denis le Petit († 530/550), la traduction de la définition de foi de Chalcédoine, des 
suscriptions et canons afférents ne serait pas de lui, mais un complément postérieur ${ }^{23}$.

Les collections « idéologiques » organisent les documents en fonction des partis pris de leurs auteurs et des fins de propagande qui ont guidé leur conception. Elles réunissent des textes d'origine grecque, latine, syriaque et puisent surtout dans les collections interconciliaires de deuxième et troisième génération. Une même collection peut se trouver au croisement de plusieurs influences, telle la collection Veronensis qui servit d'abord contre la politique du pape Anasthase II († 498), puis aux opposants aux Trois Chapitres et aux partisans du schisme d'Aquilée ${ }^{24}$. Certaines suivent de près le contenu des collections archétypales, comme la collection de Tours des actes d'Éphèse. Les collections " romaines » sont destinées à éclairer le pape ou à appuyer son point de vue ${ }^{25}$, d'autres, " partisanes », comme la Veronensis déjà citée, ou les collections monophysites ou nestoriennes, nourrissent l'argumentaire des partis opposés ${ }^{26}$.

Certaines collections, que nous appellerons « génériques » réunissent enfin des documents choisis en fonction de leur genre littéraire, extraits d'autres recueils : canons ayant trait à un ou plusieurs conciles, florilèges et dossiers théologiques, gesta synodalia, lettres comme celles de saint Léon $(A C O, 2 / 4)$. Ainsi les Fausses décrétales pseudo-Isidoriennes dériveraient de la Collectio Casinensis ${ }^{27}$.

Les collections imprimées scientifiques modernes se détachent de ce vaste ensemble de sources manuscrites. Souvent bilingues, voire synoptiques (Labbé, Mansi), elles cherchent à reconstituer artificiellement les dossiers propres à chaque concile ${ }^{28}$. Pour ce faire, les éditeurs

23 ACO, 2/2, p. 155-169; cf. ACO, 4/3/1, p. 209 et les arguments de E. SchwarTz dans ACO, 2/2, p. xVIII.

24 Voir plus haut n. 11.

25 Par exemple, la collection Novariensis de re Eutychetis composée à partir d'archives romaines. Vérone [US] Tour [T] et Palatin 38 [P] ont des parties communes, mais T a été révisé sur le grec $(A C O, 1 / 2, \mathrm{p}$. vi).

26 Pour un aperçu plus détaillé de cette classification, voir A. GRILLmeler, Le Christ dans la tradition, op. cit., p. 44-53.

$27 \mathrm{KI}$. ZeCHIEL-ECKES, « Verecundus oder Pseudoisidor? Zur Genese der Excerptiones de gestis Chalcedonensis concilii », Deutsches Archiv für Erforschung des Mittelalters, t. 56, 2000, p. 413-446, ici p. 414.

28 Les tables synoptiques de $A C O, 4 / 3 / 1$, p. 539-579 permettent une comparaison des éditions anciennes. Sur les éditions parues à la suite de J. Marlin (Paris, 1524), Crabbe, Surius, Nicolini, Bollanus, Baluze, Hardouin, Coleti et Mansi, voir H. Quentin, Jean Dominique Mansi et les grandes collections conciliaires. Étude d'histoire littéraire suivie d'une correspondance inédite de Baluze avec le Cardinal Casanate et de lettres de Pierre Morin, Hardouin, Lupus et Montfaucon, Paris, 1900. 
ont donc souvent " cassé » I'unité originelle des collections génétique de deuxième génération. II faudra attendre les $A C O$ pour que le respect des collections originales devienne le principe de base de l'édition des actes des conciles.

Enfin, les plus répandues, les collections manuelles destinées aux théologiens et au grand public, sont surtout des florilèges chronologiques, plus ou moins étendus, destinés à rassembler les « lieux théologiques » de l'enseignement magistériel solennel, tel qu'il est compris désormais à la suite des constitutions Pastor aeternus de Vatican I et Lumen gentium de Vatican II qui articulent l'infaillibilité du pape et le magistère collégial des évêques. L'édition de Giuseppe Alberigo (reprise notamment par la Library of Latin Texts des éditions Brepols ${ }^{29}$ ) est réservée aux seuls décrets et constitutions conciliaires (à l'exclusion des procès-verbaux des débats), tandis que l'enchiridion de DenzingerSchönmetzer ${ }^{30}$ et celui de Gervais Dumeige ${ }^{31}$, embrassent également les textes les plus décisifs de l'enseignement des papes. Aucune de ces éditions, pas même l'édition bilingue du Cerf, ne donne accès à l'intégralité d'une collection conciliaire des six premiers conciles et ne laisse soupçonner la complexité du magma documentaire dont proviennent les textes retenus. Ces ouvrages réduisent - dramatiquement faudrait-il dire ici - la documentation conciliaire à des florilèges d'anathèmes et de définitions quasi juridiques plus ou moins argumentées.

\section{- Traductions et révisions}

La traduction fait partie intégrante de la dynamique synodale. Elle en est comme le dernier acte. Jusqu'au VII siècle au moins, presque toute la documentation conciliaire latine a été élaborée pour préparer les assemblées synodales, les informer ou orienter leur diffusion. Les papes même se faisaient traduire les actes grecs des conciles. Si on connaît le nom de certains compilateurs, les auteurs des traductions officielles sont souvent anonymes, mieux identifiés dans le cas des traductions

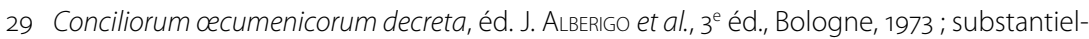
lement repris et augmenté par la traduction française des éditions du Cerf : Les conciles œecuméniques, t. I, L'histoire, trad. par J. MIGNON, Paris, 1994.

$30 \mathrm{H}$. Denzinger et A. Schönmetzer, Enchiridion symbolorum, definitionum et declarationum de rebus fidei et morum, [Würzburg, 1854], 36e éd., Barcelone/Fribourg/Rome, 1976 ; désormais avec des traductions en français et en anglais. Cf. Y. M.-J. ConGAR, « Du bon usage de Denzinger », dans Situations et tâches présentes de la théologie, Paris, 1967, p. 111-133 qui note (p. 121) la présence de citations « à contresens ou (...) d'une manière qui en altèrent le sens » jusque dans les textes du magistère moderne.

31 G. Dumelge, S. J., La foi catholique. Textes doctrinaux du magistère de l'Église, Paris, 1961 (plusieurs éditions considérablement remaniées jusqu'en 1996). 
partisanes ou érudites comme celles de Marius Mercator, Denis le Petit ou Rusticus. À Rome, les traducteurs compétents n'ont jamais manqué. Marius Mercator puis Denis le Petit, moine scythe, connaissaient le grec et le latin et travaillaient à Rome ${ }^{32}$. Rusticus, latin, a vécu à Constantinople où il a appris le grec. Il entendait faire connaître à l'Occident les textes grecs des controverses christologiques ${ }^{33}$. L'examen de la tradition manuscrite de ces traductions aide à comprendre combien les premiers conciles sont loin d'avoir été accessibles à tous de manière constante et homogène.

\section{- Éphèse et Chalcédoine}

Les papes ont dû se contenter longtemps de simples résumés. La première attestation d'une traduction latine de débats conciliaires est une lettre adressée par Léon le Grand à Julien de Cos, son légat à Constantinople, en mars 453 :

Nous avons entre les mains un compte rendu des Actes synodaux qui ont été confectionnés chaque jour dans la ville de Chalcédoine, de manière peu claire à cause de la différence de la langue. J'enjoins donc spécialement à ta fraternité de faire réunir en un volume l'ensemble, traduit très précisément en langue latine, afin que nous ne puissions avoir aucun doute sur aucune partie des sessions et qu'il ne puisse y avoir une ambiguïté d'aucune sorte sur ce que tu te seras appliqué à conduire vers une pleine intelligence ${ }^{34}$.

Les textes recueillis dans la collection Vaticana, qui ne contient plus que des extraits de quelques sessions de Chalcédoine, auraient été traduits en réponse à cette demande.

Rome n'aurait presque rien connu des discussions du concile d'Éphèse avant les traductions partielles attribuées parfois à Denis le Petit au début du $\mathrm{Vl}^{\mathrm{e}}$ siècle $^{35}$. La plus ancienne traduction latine complète vit le jour vers 550 à Constantinople lorsque, la controverse s'élevant au sujet

32 J. Rambaud-Bunot, « Denys le Petit », Dictionnaire de droit canonique, t. 4, 1949, col. 1131-1152.

33 Préface à la traduction de la seconde lettre de Cyrille à Nestorius ( $P L, 67$, col. 9-18) (anathématismes).

34 Ep. 34 (PL, 130, col. 814A; ACO, 2/4, p. 62) : Gestorum synodalium que omnibus diebus concilii Chalcedonensi civitate congecta sunt parum clara, propter lingue diversitatem, apud nos habetur instructio. Et ideo fraternitati tue specialiter iniungo ut in unum codicem universa facias congregari in latinum, scilicet sermonum absolutissima interpretatione translata, ut in nulla parte actionum dubitare possimus, neque ullo modo esse possit ambiguum quod ad plenam intelligentiam te fuerit studente perductum.

35 A. Grillmeler, Le Christ dans la tradition, op. cit., p. 50 ; cf. J. Rambaud-Buhot, « Denys », op. cit., col. 1143-1144. 
des Trois Chapitres entre Justinien et les évêques occidentaux, les partisans de Cyrille jugèrent utile de permettre à ces derniers de se faire une idée de l'ensemble de la controverse. Sans tenir compte des traductions de Denis qu'elle semble ignorer, cette traduction, dite de Tours $(T)$, a pris le nom du lieu de provenance du manuscrit acquis par Baluze (1630-1718) à Saint-Julien de Tours. Aujourd'hui conservée à Paris ( $T / p)$, elle est plus probablement originaire d'une abbaye du centre de la France (peutêtre Micy) ${ }^{36}$. Dans le même temps et dans le même contexte, les actes de Chalcédoine furent également traduits en latin à Constantinople, à l'exception de la seizième session. On désigne cette version par le sigle $\Phi^{A}$ (versio antiqua). Elle fut ensuite révisée et assortie d'un dossier de correspondances doctrinales (Epistularum ante gesta collectio, ACO, 2/3/1) avec lequel elle forme la version $\Phi^{c}$, attribuée à tort, à Rusticus qui ne fit que la réviser $\left(\Phi^{\mathrm{R}}\right)$. Ces trois versions des actes d'Éphèse et Chalcédoine attestent, dès la seconde moitié du Vle siècle, une conscience aiguë des problèmes de traduction.

C'est entre le 21 février 564 et le $1^{\text {er }}$ avril 566 , probablement après la mort de Justinien en 565, que Rusticus, diacre romain, neveu du pape Vigile († 555) avec lequel il s'était rendu à Constantinople au moment du cinquième synode, rassembla les documents qui composent la collection que, depuis Baluze, on appelle Casinensis. Son intention était de prendre la défense des accusés des Trois Chapitres et s'opposer aux Dioscoriens qui se présentaient comme disciples de Cyrille ${ }^{37}$. Son entêtement dans cette voie lui valut la disgrâce de l'empereur et l'excommunication de son oncle. Son travail consista d'abord à regrouper les actes d'Éphèse et Chalcédoine (sauf la $16^{e}$ session), à leur adjoindre un important dossier de lettres et d'actes concernant les controverses christologiques d'Éphèse, trouvés dans la bibliothèque du monastère des Acémètes de Constantinople ${ }^{38}$, traduits et rassemblés dans la seconde partie du Synodicon $(A C O, 1 / 4)$, enfin et surtout à réviser, à partir de manuscrits grecs, la Vetus d'Éphèse (de T vers $C)^{39}$ et celle de Chalcédoine (de $\Phi^{A}$ vers $\left.\Phi^{R}\right)^{40}$. Déposé au monastère des Acémètes, son recueil fit l'objet de nouvelles copies. Les rubriques des manuscrits attestent son intervention : Nunc incipiunt gesta prima

36 Trois autres manuscrits paraissent en dériver (T/a T/i T/q). Cf. E. SCHWARTZ, ACO, 1/3, p. IX-XII.

37 E. SCHWARTZ, ACO, 1/4, p. vill et ACO, 2/3/1, p. 27 et 2/3/3, p. 561.

38 Fondé en 440 pour le service de la prière continuelle, c'était un centre de diffusion littéraire très important et le lieu de ralliement du parti chalcédonien durant la querelle monophysite.

39 CF. E. SCHWARTZ, ACO, 2/3, p. I-XVI.

40 Voir annexe 3. 
concilii Calcedonensis. Rusticus ex latinis et grecis exemplum maxime Acoemit<orum > Monast<erii> emendavit.

La collection, reconstituée par Schwartz, réunit quelques 194 pièces en latin $(A C O, 1 / 3-4)$, mais les manuscrits de la collection ne présentent pas une physionomie homogène. Aucun n'en conserve l'intégralité. À l'instar d'un corps céleste dont les éléments désintégrés auraient été attirés dans l'orbite d'autres astres, les trois versions des actes de Chalcédoine ont éclaté et ont été associées à des traductions d'autres origines avec lesquelles elles sont restées en partie accessibles grâce à d'assez nombreuses copies ${ }^{41}$. Seuls les actes d'Éphèse traduits par Rusticus ne sont plus connus que par les deux manuscrits du Vatican et du Mont-Cassin. Le manuscrit 2 du Mont Cassin $(\mathrm{C} / \mathrm{m})$, qui avait donné son nom à la collection, ne contient pas la version de Chalcédoine révisée par Rusticus ${ }^{42}$. Seul le manuscrit Vatican latin $1319(\mathrm{C} / \mathrm{V})^{43}$, assemblage composite d'éléments copiés dans le nord de l'Italie dans la seconde moitié du XII siècle, a contenu un temps les actes d'Éphèse et de Chalcédoine révisés par Rusticus ${ }^{44}$. Tous deux furent copiés à partir d'exemplaires différents et par plusieurs mains. En effet, dans $\Phi^{c} / \mathrm{m}$, une lacune de plusieurs cahiers - correspondant à $A C O, 2 / 3$, p. 158$176_{26}$ - a été remplacée partiellement (p. $158_{3}-17 \mathrm{O}_{29}$ ) par un texte copié sur $\Phi^{R} / C^{45}$, car il reproduit les accidents matériels des rubriques qu'on peut encore y observer. Ce dernier manuscrit, le meilleur témoin de la version de Rusticus pour Chalcédoine, a probablement été copié à Corbie, d'où il passa tardivement à l'abbaye de Saint-Germain-des-Prés qui l'abrita jusqu'à la Révolution. Par conséquent, $\Phi^{c / m}$ ne pourrait avoir que la même origine ${ }^{46}$. Mais le modèle du reste du manuscrit doit être différent, puisque sa version des actes de Chalcédoine suit la versio antiqua correcta $\left(\Phi^{\mathrm{C}}\right)$, tandis que $\Phi^{\mathrm{R}} / \mathrm{C}$ transmet la versio antiqua correcta

41 Voir le tableau synoptique publié dans M. MorarD, «Thomas d'Aquin lecteur des conciles», op. cit., p. 216-217.

42 Bibliotheca Casinensis seu codicum manuscriptorum qui in tabulario Casinensi asservantur series... cura et studio monachorum ordinis s. Benedicti abbatiae Montis Casini, t. I, Monte Cassino, 1873, p. 49-84 et pl. II ; M. InguAnEZ, Codicum Casinensium manuscriptorum catalogus cura et studio monachorum s. Benedicti... Montis Casini, t. I-1, Monte Cassino, 1915, p. 4-5.

43 C. H. TURner, « Notes on the contents of Vatic. Lat. 1319 », Journal of theological studies t. 6, 1905, p. 85-86.

44 Il fut examiné à Rome pour la première fois par Jacques Sirmond entre 1590 et 1618 (ACO, $1 / 4$, p. xv).

45 Paris, BnF, lat. 11611, IXe siècle; cff. Kl. ZeCHEEL-ECKES, «Verecundus oder Pseudoisidor? », op. cit., p. 416.

46 E. SCHWARTZ, ACO, 2/3/1, p. X. 
et edita a Rustico $\left(\Phi^{\mathrm{R}}\right)$. Avec un contenu identique, hormis une lacune accidentelle, le manuscrit du Vatican (v) descend également de $\Phi^{R} / C$. Contrairement à ce que j'ai publié ailleurs à tort, sur la foi de Schwartz, l'observation directe du manuscrit atteste, sans doute possible, que les actes d'Éphèse et la fin de Chalcédoine ont été copiés et décorés en Italie, probablement à partir d'un modèle commun importé de Corbie ${ }^{47}$.

Malgré le temps très court qui avait séparé les traductions primitives de leur révision par Rusticus, T, $\Phi^{A}$ et $\Phi^{C}$ eurent leur propre diffusion ${ }^{48}$ qui donna lieu à des formes intermédiaires entre $\Phi^{A}$ et $\Phi C^{49}$. La révision effectuée par Rusticus a elle-même fait l'objet de corrections médiévales et d'interpolations plus tardives. De nombreuses copies partielles, carolingiennes et médiévales, comportent des variantes reportées en marge. Dans les marges des premières pages des actes d'Éphèse $(\mathrm{C} / \mathrm{m})$, un correcteur, différent du copiste, a ajouté une grande quantité de leçons dont une minorité s'accorde avec deux témoins tardifs de la Collection de Tours $(\mathrm{T} / \mathrm{iq})^{50}$. Dans $\Phi^{\mathrm{R}} / \mathrm{v}$, de nombreuses lignes ont été grattées et corrigées à partir d'un manuscrit non identifié, ce qui oblige à postuler l'existence, au XIII' siècle, d'au moins un autre témoin et d'une quatrième "version » des actes de Chalcédoine ${ }^{51}$. Le plus souvent, il s'agit de corrections orthographiques ou grammaticales amenées motu proprio par le copiste. On soupçonne parfois une correction faite sur le grec, mais la rareté des actes grecs empêche de le démontrer. Les manuscrits homogènes sont l'exception, surtout pour Chalcédoine. Les révisions ont aussi été l'occasion de remaniements du contenu des collections. Ainsi, la version corrigée de Chalcédoine $\left(\Phi^{\complement}\right)$ déplace les canons à la fin des actes, et non, comme dans la version grecque et la Vetus, à la fin de la sixième action. Schwartz a démontré que cela avait été pensé par les opposants à Constantinople Il, défenseurs des Trois Chapitres ${ }^{52}$.

\section{- Constantinople II}

Les querelles post-chalcédoniennes ont été l'occasion des principales traductions latines des cinq premiers conciles qui furent reçues à partir de la seconde moitié du XIII' siècle avec l'autorité de textes quasi

47 E. Schwartz, ACO, 2/3, p. x\|l et M. MoRARD, «Thomas d'Aquin lecteur des conciles », op. cit., p. 222-223.

48 E. SChwarTZ, $A C O, 2 / 3 / 1$, p. VIIIXIII.

49 Ibid., p. XI.

50 E. SChWARTZ, ACO, 1/3, p. I.

51 E. SCHWARTZ, ACO, 2/3/1, p. VIII.

52 ACO, 2/6, p. xvIII; cf. Abhandlg. d. Bayer. Akad. d. Wiss., t. 32, n² 2, p. 18. 
authentiques. Dès 553, Vigile, qui évoque lui-même auprès de Justinien son ignorance du grec, disposait au moins de la traduction de la Sententia synodica et des canons ${ }^{53}$. Celle-ci appartient sinon à une entreprise de propagande, comme l'écrit Aloys Grillmeier, du moins à un mouvement de prise à parti du clergé occidental opposé à Justinien ${ }^{54}$. Elle a servi à faire comprendre les enjeux du débat oriental. L'authenticum de Constantinople II, rédigé en grec, avait encore été cité comme tel au cours des sessions de Constantinople III. Mais la dramatique de Constantinople II, jointe aux falsifications monothélistes signalées plus haut, ont contribué à l'effacement presque complet de sa mémoire, souvent réduite aux seuls anathématismes conservés dans les collections canoniques ${ }^{55}$. On ne connaît plus aujourd'hui Constantinople II que par un seul manuscrit de sa traduction latine $(\mathrm{N})$, copié au IXe siècle dans le nord de la France, donné en 1680 à la bibliothèque du chapitre cathédral de Notre-Dame de Paris par le chanoine Claude Joly (1607-1700) qui en avait hérité avec les livres de son oncle, l'avocat Antoine Loisel $(† 1617)^{56}$. Ce dernier l'avait « emprunté » à Saint-Pierre de Beauvais, cathédrale

53 VIGILE, Ep. 83 (Constitutum I) in Epistulæe imperatorum pontificum aliorum inde ab a. ccCLXVII usque a. DLIII datæ Avellana quæe dicitur collectio, éd. O. GuentHER, Prague/Vienne/Leipzig, 1895 (CSEL, 35), p. 230-320, ici p. 297 2 : Quia graecae linguae - sicut cunctis, et maxime pietati vestrae, notum est - sumus ignari. Une lettre du pape Pélage II, vers 585 , fait plusieurs citations de cette traduction: Pelage, lettre Virtutum mater, ACO, 4/2, 112 15 -132 37 ; MANSI, col. 434-454.

54 A. Grillmeler, Le Christ dans la tradition, op. cit., p. 41-54, ici p. 46.

55 Seuls quelques fragments de la sentence synodique, 14 canons et quelques lettres subsistent encore en grec. Voir références dans $A C O, 4 / 3 / 1, p .520$. Le texte latin de la $7^{e}$ session dit par ailleurs que les lettres du pape Vigile à l'empereur ont été traduites en grec: Omnibus translatis ad grecam linguam ad faciliorem scientiam vestrae sanctitatis (ACO, 2/1, p. 184 $\left.{ }^{28}\right)$. D'après P. Gray, art. « Konstantinopel, Ökumenische Synoden von 553 », Theologische Realenzyklopädie, t. 19, 1990, p. 525, les actes synodaux grecs ayant disparu après le $6^{e}$ concile œcuménique, "das Gedächtnis der Synode heftete sich allein an ihre Anathmatismen »; « ... doch blieb eine anhaltende Unsicherheit über die echten Synodalakten bestehen » (p. 526). Sur la transmission manuscrite des actes de Constantinople Il et ses aléas, voir J. STRAUB, ACO, 4/1, p. VIIIXXIII ; R. SCHIEFFER, dans Zeitschrift der Savigny-Stiftung für Rechtsgeschichte. Kan. Abteilung, 1973, p. 1-34 et C. HEFELE et H. LECLERC, Histoire des Conciles, t. III-2, p. 1200 ; cf. aussi ici n. 14.

56 Paris, BnF, lat. 16832 ; description dans ACO, 4/1, p. vII-VIII. Sont perdus les manuscrits qui ont servi à établir l'édition de 1567 du chartreux Surius (s), et le manuscrit de Beauvais (b) utilisé par Baluze. Au fol. $124 r^{\circ}$, une note autographe atteste de son utilisation par Baluze : Contuli. Absolvi VI. Kalend. April. MDCLXXXIII. Stephanus Baluzius. Mais son contenu ne correspond pas au manuscrit de Beauvais cité par Baluze, aujourd'hui considéré comme perdu, qui contenait les actes de Constantinople II et la Collectio Palatina (cf. ACO, 4/1, p. Ix ; ACO, $1 / 5$, p. v). - Les inventaires de la bibliothèque de Notre-Dame, au XIIIe siècle et en 1756, lors de son acquisition par la Bibliothèque royale, ne mentionnent aucun autre manuscrit conciliaire (cf. L. DeLISLE, Le cabinet des manuscrits de la Bibliothèque nationale, t. III, Paris 1881, p. 1-5 et A. Franklin, Les anciennes bibliothèques de Paris, t. I, Paris, 1867, p. 13-18). 
de sa ville natale, comme en témoignent les bordereaux de prêt de la célèbre bibliothèque capitulaire étudiés par Charlotte Denoël ${ }^{57}$. II contient dans sa première partie la version $\Phi^{A}$ de Chalcédoine, puis, sur deux colonnes, les actes du cinquième synode avec les deux Constituta de Vigile. Ce manuscrit est le seul témoin complet de la version longue ${ }^{58}$. Encore marqué par les traces du schisme qui divisa le pape et l'empereur à l'occasion des Trois Chapitres, il véhicule une version du concile antérieure à leur réconciliation qui se solda par la mise au point d'un texte expurgé, seul réellement diffusé avant la découverte de Baluze ${ }^{59}$. Le Constitutum I/ de Vigile en est absent. Son unique témoin est placé au milieu d'une collection de lettres qui concernent ce concile (Parisiana). Voilà qui met en valeur l'originalité de la documentation de Thomas d'Aquin. Voilà aussi qui aide à comprendre la difficulté des théologiens médiévaux à en mesurer l'exacte portée ${ }^{60}$.

\section{- Constantinople III}

Les actes de Constantinople III bénéficient d'une tradition beaucoup plus fournie. Au Latran (649), les moines grecs de Rome et l'entourage de Maxime le Confesseur commencèrent par rédiger en grec le texte du synode pour des raisons politiques : le concile visait d'abord Justinien II et les monothélistes byzantins ; leur traduction latine fut faite dans un second temps par un Grec qui ne maîtrisait pas parfaitement le latin. À Constantinople III, le premier notaire fut expressément chargé d'aller chercher les anciens actes dans les archives et de les lire. Seule l'épitre synodique du pape Agathon et la lettre adressée par le synode romain ont été composées en latin, puis traduites en grec à Constantinople. Les autres textes latins ont été traduits à partir de l'authentique grec à Rome vers 682-701 par des Grecs qui savaient mieux le grec que le traducteur du synode du Latran. Onze manuscrits latins se rattachent à cette première

57 BnF, mss., Picardie 162, fol. 152 $v^{\circ}$, d'après Ch. DenoëL, « Le fonds des manuscrits latins de Notre-Dame de Paris à la Bibliothèque nationale de France », Scriptorium, t. 47, 2004, p. 131-173, ici p. 151 n. 104 et p. 162.

58 VIGILE, Ep. 83 (Constitutum I), op. cit., p. LXIX-LXXIV.

59 Cf. S. Baluzius, Prefatio in acta Concilii V, dans Mansı, t. 9, col. 163A. Les principales variantes rédactionnelles se trouvent dans les sessions 1, 2 et 7, ACO, 4/1, p. 199 $29_{21} 202_{21^{\prime}}$ etc. Elles ne paraissent pas affecter les passages cités par Thomas d'Aquin. Sur la problématique historique du concile, voir E. AmAnN, «Trois-Chapitres (affaire des) », Dictionnaire de théologie catholique, t. XV-2, 1950, col. 1868-1924, ici col. 1904-1906, avec les remarques de Ch. Moeller, "Le cinquième concile œcuménique et le magistère ordinaire au Vle siècle », op. cit.

60 Paris, BnF, lat. 16832, fol. 1-54, 58-73 (ACO, p. 101-184) ; Constitutum II : Ex Vigili papae epistula de tribus capitulis, fol. $27 \mathrm{v}^{\circ}-54 \mathrm{~V}^{\circ}$. 
traduction ; ils appartiennent à quatre familles différentes, et ont été copiés vers la fin du VIII ${ }^{e}$ siècle dans la région de Reims-Laon, SaintAmand, et au IX siècle au nord de l'Italie (Bobbio-Nonantola). Le PseudoIsidore y a évidemment puisé. La famille italienne atteste de corrections effectuées sur le grec ${ }^{61}$. Les manuscrits de la tradition grecque, répartis en 3 familles, sont plus récents : le meilleur manuscrit date de 1446 , le plus ancien date du début du XIle siècle, mais remonte à l'édition faite en 713 par le diacre Agathon qui avait participé au concile comme archiviste, après que l'empereur Philippikos Bardanes ait ordonné en 711 la destruction des actes originaux.

\section{- Diffusion médiévale}

En résumé, tous les témoins directs des collections archétypales ont disparu. Les collections grecques sont généralement conservées par des manuscrits plus tardifs que leurs sœurs latines. On observe une grande disparité numérique et chronologique entre les témoins grecs et latins des collections de seconde et troisième génération. Jusqu'à l'affaire des Trois Chapitres, les recueils d'actes officiels, grecs, étaient restés en Orient, Rome ne disposant que de collections partielles. Les échanges se faisaient par lettres et florilèges. L'affaire des Trois Chapitres a servi de leçon : la diffusion des actes de Constantinople II dans le monde latin au travers de collections partisanes entretint la polémique. À partir de la querelle monothéliste, les archives pontificales conservent des actes latins complets. Mais pour peu de temps. Aucun témoin antérieur au $\mathrm{VIIII}$ siècle ne subsiste. Les déplacements des papes, les invasions, la fragilité du papyrus utilisé par la chancellerie pontificale jusqu'à seuil de I'an mil ${ }^{62}$, les destructions des archives pontificales de la fin du XIIe siècle et du XIII' siècle achèvent de faire disparaître ce que Rome avait pu garder. L'Italie, par ailleurs si riche, conserve peu de manuscrits latins des conciles copiés entre le VIII ${ }^{e}$ siècle et le troisième quart du XII ${ }^{e}$ siècle, bien qu'entre le VII et la seconde moitié du XII siècle, les relations entre Rome et l'Empire aient été l'occasion de nombreux échanges. Au IXe siècle, Anasthase le Bibliothécaire compila et traduisit à Rome nombre de textes grecs. On ne compte plus les traducteurs allant à Constantinople pour copier les originaux d'œurres diverses : Moïse de Bergame, Jacques de Venise, Burgondio de Pise, Pascal de Rome, mais aussi les parisiens Léon

61 ACO, ser. 2/1, p. XI.

62 À propos du problème posé par la rareté des manuscrits d'actes conciliaires latins, je me permets de renvoyer encore à mon étude : «Thomas d'Aquin lecteur des conciles », op. cit., p. 344-351. 
et Hugues Éthérien, futur cardinal de Saint-Ange $(\dagger 1182)^{63}$. On connaît la lettre, datée probablement de 1176-1177, par laquelle le cardinal Aymeric de Limoges, patriarche latin d'Antioche (1140 à 1165, 1170-1193, †1196), demanda à Hugues, alors à Constantinople, de lui envoyer la practica,

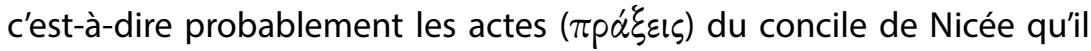
croyait conservés au Palais impérial ${ }^{64}$.

Dans le reste du monde latin, les lieux forts de la conservation des collections conciliaires sont principalement Corbie et Beauvais, Laon et Reims d'où proviennent les manuscrits copiés en Italie à la fin du XIle siècle : manuscrits de la Casinensis et de la troisième famille de Constantinople III. Aux XIle et XIII siècles, les auteurs prennent conscience de la nécessité de recourir aux originaux grecs quand ils sont accessibles. II ne restait rien alors de l'ancienne bibliothèque pontificale du Latran. Les papes dans leurs déplacements avaient d'autres choses à emporter que les archives de querelles closes. Ce sont les bibliothèques des ordres religieux et des chapitres cathédraux qui ont conservé la mémoire des premiers conciles. C'est là que se rendit Thomas d'Aquin, mu par un "sens historique " peu commun à son époque ${ }^{65}$. Pour composer la Catena aurea, au début des années 1260, il se fit traduire des chaînes exégétiques byzantines comme celle de Nicétas ${ }^{66}$ et des œuvres qui étaient encore inaccessibles aux latins comme les commentaires bibliques de Théophylacte de Bulgarie ${ }^{67}$. Pour les conciles, vu la carence des témoins originaux, il se contenta d'éléments de la

63 R. LECHAT, «La patristique grecque chez un théologien latin du XIle siècle, Hugues Éthérien », in Mélanges d'histoire... Ch. Moeller, Louvain/Paris, 1914, t. I, p. 484-507 et A. DondAINE, "Hugues Éthérien et Léon Toscan », dans Archives d'histoire doctrinale et littéraire du Moyen Âge, t. 19, 1952, p. 67-134.

64 Rescriptum Aimerici ad Hugonem, PL, 202, col. 232A : Practica Nicaeni concilii quam audivimus esse penes dominum imperatorem. Cf. A. BLAISE, Lexicon latinitatis Medii Aevi, 1975, art.

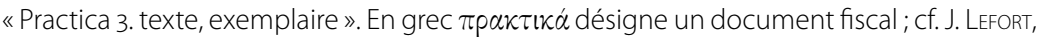
"Observations diplomatiques et paléographiques sur les praktika du XIVe siècle », dans La paléographie grecque et byzantine, colloque international du CNRS $n^{\circ} 559$, Paris, 1977, p. 461-472. Voir, sur cette lettre, A. DondaINE, « Hugues Éthérien et le concile de Constantinople de $1166 »$, Historisches Jahrbuch, t. 77, 1957, p. 473-483.

65 Sur le rapport de Thomas à l'histoire, voir J.-P. ToRRELL, « Saint Thomas et l'histoire. État de la question et pistes de recherches », Revue thomiste, t. 105, 2005, p. 355-409.

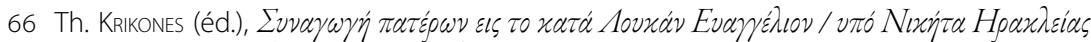

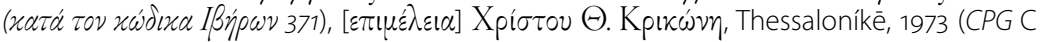
135).

67 C. G. Conticello, «San Tommaso ed i Padri : la Catena aurea super loannem », Archives d'histoire doctrinale et littéraire du Moyen Âge, t. 65, 1990, p. 32-92. ; ID., "Théophylacte de Bulgarie, source de Thomas d'Aquin (Catena aurea in loannem)», dans Philomathestatos: Studies in greek and byzantine texts presented to Jacques Noret for his sixty-fifth birthday, éd. B. Janssens, B. Roosen et P. van Deun, Louvain/Paris/Dudley, 2004, p. 63-75. 
collection Casinensis et des traductions de Constantinople II et III. Certes, il s'est laissé « tromper » en lisant Chalcédoine à la lumière de Constantinople II. Celui qui préférait croire qu'un bœuf puisse voler plutôt qu'un dominicain mentir, pouvait-il imaginer qu'un concile ne rapporte pas fidèlement la teneur d'un autre concile? Les textes qui lui servirent à étayer certaines de ses positions christologiques découlent en partie de la lecture d'actes conciliaires biaisés par les polémiques de Constantinople II, dans une version non approuvée pro forma par l'autorité pontificale. II prêta à la troisième lettre de Cyrille à Nestorius une approbation synodale qu'elle n'avait pas reçue.

En conséquence, il qualifiera d'hérétique le troisième modèle explicatif de l'union des deux natures dans le Christ : la théorie de l'Assumptus homo proposée par Pierre Lombard comme explication de l'union des deux natures dans le Christ ${ }^{68}$. Dans son sillage, la troisième lettre de Cyrille à Nestorius est donc apparue à ses lecteurs comme une définition conciliaire de la foi, d'une part parce qu'on n'a pas tenu compte du fait que le pape Vigile avait soumis son approbation des actes de Constantinople II à leur stricte conformité à la teneur de Chalcédoine, d'autre part parce que Thomas d'Aquin a pris la relecture tendancieuse de Constantinople II pour argent comptant, sans en vérifier l'exactitude dans les actes intégraux de Chalcédoine. Elle eut pour conséquence d'accentuer la teneur anti-nestorienne de la théologie occidentale ${ }^{69}$. Bref, la réception de Constantinople II comme œcuménique, qui avait

68 Sum. theol. III q. 25 a. 1 co. Pour l'analyse intégrale et détaillée des citations conciliaires de Thomas, on voudra bien se reporter encore à notre étude : «Thomas d'Aquin lecteur des conciles », op. cit., en particulier p. 268-269 (citations de l'Epistola synodica 3 «Salvatore») et p. 282-285. Si Thomas avait eu sous les yeux la collection Casinensis $(A C O, 1 / 3-4 ; 2 / 3)$, il aurait pu remarquer que la lettre est absente des actes de Chalcédoine, comme il est facile de le voir dans le manuscrit du Mont Cassin où les titres rubriqués permettent un repérage commode. Malgré cela il soutient avec insistance que la $3^{\mathrm{e}}$ lettre de Cyrille à Nestorius et ses anathématismes expriment la doctrine d'Éphèse, sous prétexte que Chalcédoine entérina expressément les synodiques de Cyrille. Voir par exemple Contra Gentiles, IV 24, ed. Leon. 15, p. 91a ${ }_{18-21}$ : Cyrillus etiam in epistola sua quam synodus Chalcedonensis recepit dicit : "Spiritus veritatis nominatur et est Spiritus veritatis et profluit ab eo sicut denique et ex Deo Patre $=A C O, 1 / 3$, p. $32_{25-27}$. Sum. theol. III q. 2 a. 3 co. : Et hoc etiam damnatum est approbante concilio Ephesino sub hiis verbis: "Si quis [4 anathématisme] $=A C O, 1 / 3$, p. 34 4 . La $2^{\mathrm{e}}$ session n'a approuvé que les deux premières lettres de Cyrille à Nestorius et la lettre à Jean d'Antioche. La $3^{e}$ lettre à Nestorius n'a été ni reproduite, ni même mentionnée dans la première session où furent « récités » les actes d'Éphèse, ni dans la suivante, quand les lettres de Cyrille approuvées à Éphèse furent lues devant les pères. La $4^{e}$ session mentionne l'approbation de deux lettres de Cyrille, sans permettre de les identifier.

69 Pour une lecture panoramique de la christologie thomasienne, nous renvoyons à J.-P. ToRrelL, Jésus le Christ chez saint Thomas d'Aquin, Paris, 2008, en souvenir du maître qui sut 
fini par s'imposer au Moyen Âge, contribua à faire accepter sa relecture des conciles antérieurs, au point de faire oublier la non conciliarité de la troisième lettre de Cyrille. Personne alors ne disposait d'un recul suffisant pour éviter l'obstacle. La méprise, pour compréhensible qu'elle soit, procédait de cette approche globalisante et harmonisante qui conduit parfois à confondre documentation conciliaire et doctrine des conciles. Même chez les mieux informés, une connaissance historique déficiente peut aboutir à conférer à des erreurs l'autorité du Saint-Esprit. C'est que, pour le théologien, ni le droit, ni même les textes de l'Écriture et de la Tradition n'imposent seuls la norme de la foi, qui leur est supérieure et qui seule fait loi, in consensu fidelium.

Depuis Thomas d'Aquin, les théologiens ont cherché le sens des définitions dogmatiques des conciles dans les explications que les pères conciliaires eux-mêmes en avaient donné au cours des sessions qui préparaient les votes qu'ils soumettaient à l'approbation de leurs pairs $^{70}$. Aujourd'hui encore, les théologiens interprètent les documents de Vatican II à la lumière des modi conservés dans les Acta synodalia officiels ${ }^{71}$.

Tout concile est la mise en scène, puis la mise en texte, d'un « drame » en plusieurs « actes » dont l'objet est la définition des principales expressions qui garantissent l'unité doctrinale de l'Église. Les collections latines de textes des premiers conciles appartiennent à la geste synodale et intersynodale. Si elles ont l'apparence d'une documentation neutre et objective, dans les faits, ce sont les pièces d'un débat, tantôt issues des mouvements que les conciles étaient censés avoir contrôlé, tantôt nées des questions qu'ils n'avaient pas encore tranchées. Si elles sont la mémoire écrite de la proclamation communautaire et sacrée de la foi de l'Église, sans cesse réactualisée, elles ont été conçues et diffusées dans une intention de propagande partisane, et non comme des instruments authentiques et officiels. Alors que les pères synodaux n'ont pouvoir que sur le processus d'élaboration des actes, la traduction et la mise en recueil de ceux-ci sont le fait d'agents sans mission ecclésiale spécifique qui ont influencé la réception des conciles, puisque les théologiens du Moyen Âge leur ont accordé la même confiance qu'à des actes authentiques.

éveiller jadis notre intérêt pour une mise en perspective à la fois historique et théologique des conciles et de Thomas.

70 Voir à ce sujet les remarques de Y. J.-M. CongAR, « Du bon usage», op. cit., p. 123.

71 Acta Synodalia Sacrosancti Concilii Oecumenici Vaticani Il, 39 vol.., Cité du Vatican, 1970-1999. 
C'est dans ce sens aussi que le titre de ces pages reprend l'adage selon lequel le Saint-Esprit écrit droit avec des lignes courbes.

Les actes des conciles sont les révélateurs de quelque chose qui les transcende. Leur message a traversé le prisme des collections polémiques. Il n'a pas été arrêté par les aléas de la transmission des textes. Sans cesse assimilé et reformulé par l'enseignement ecclésial, il donne l'impression qu'on a pu, par le passé, lire les conciles autrement sans pour autant croire autre chose. Le fait est que le contenu de la foi ne peut être réduit à la matérialité d'autorités textuelles, qu'il s'agisse de l'Écriture ou de conciles. Il appartient au patrimoine immatériel d'un consensus d'ordre culturel qui se réfère à des documents sans qu'aucun ne l'épuise jamais. II n'y a que le développement des techniques de reproduction mécanique qui a pu faire croire à la chimère d'une source écrite unique, flottant au-dessus des drames de l'histoire.

Annexe 1: Les six premiers conciles

\begin{tabular}{|c|c|c|c|c|c|}
\hline & dates & synodus & $\begin{array}{c}\text { nombre } \\
\text { de sessions }\end{array}$ & $\begin{array}{l}\text { Édition latine } \\
\text { ACO }\end{array}$ & sujet/hérésie jugée \\
\hline Nicée l & 325 & prima & 1 & $\begin{array}{l}\text { pas d'actes } \\
\text { conservés }\end{array}$ & arianisme \\
\hline Constantinople I & 381 & secunda & $?$ & $\begin{array}{l}\text { pas d'actes } \\
\text { conservés }\end{array}$ & divinité du Saint-Esprit \\
\hline Éphèse & 431 & tertia & 3 & $A C 0,1 / 3-4(+5)$ & $\begin{array}{l}\text { nestorianisme, } \\
\text { divinité du Christ }\end{array}$ \\
\hline Chalcédoine & 451 & quarta & $\begin{array}{l}17 \text { actiones [ } 19 \\
\text { en grec] }\end{array}$ & $A C O, 2 / 3$ & $\begin{array}{l}\text { monophysisme } \\
10 u 2 \text { natures dans le } \\
\text { Christ? }\end{array}$ \\
\hline Constantinople II & 553 & quinta & 8 actiones & $A C O, 4 / 1-2$ & $\begin{array}{l}\text { monophysisme } \\
\text { Théodore de Mopsueste, } \\
\text { Théodoret de Cyr, Ibas } \\
\text { d'Édesse }\end{array}$ \\
\hline [Latran] & 649 & & 5 secretarii & ACO, ser. 2 t. 1 & \multirow{2}{*}{$\begin{array}{l}\text { monothélisme : } 10 u 2 \\
\text { volontés dans le Christ? }\end{array}$} \\
\hline Constantinople III & 681 & \multirow[t]{2}{*}{ sexta } & 18 actiones & ACO, ser. 2 t. 2 & \\
\hline $\begin{array}{l}\text { [in Trullo/ } \\
\text { Quinisexte] }\end{array}$ & 691 & & & ACO, ser. 2 t. 4 & $\begin{array}{l}\text { annexe disciplinaire de } \\
\text { Constantinople III }\end{array}$ \\
\hline
\end{tabular}

\section{Annexe 2 : Liste des collections conciliaires latines (ACO)}

1. Éphèse : Collectio Casinensis sive Synodicon a Rustico diacono compositi (ACO, 1/3-4) ; Gesta 
2. Éphèse : Collectio Veronensis $(A C O, 1 / 2)$; Gesta

3. Éphèse : Collectio Palatina sive qui fertur Marius Mercator (ACO, 1/5, p. 1-215) ; Gesta

4. Éphèse : Cyrilli epistula synodica translata par Denis le Petit $(A C O, 1 / 5$, p. 235-244)

5. Éphèse : Collectio sichardiana (ACO, 1/5, p. 247-318)

6. Éphèse : Ex collectione Quesneliana (ACO, 1/5, p. 321-340)

7. Éphèse : Collectio Winteriana (ACO, 1/5, p. 343-381)

8. Éphèse : Collectio Palatina $(\mathrm{ACO}, 1)$

9. Chalcédoine : Versio antiqua a Rustico correcta (cf. Collectio Casinensis) $(A C O, 2 / 3)$; Gesta

10 Chalcédoine : Canones Chalcedonenses secundum versiones Dionysii exigui (ACO, 2/2/1, p. 51-60)

11. Chalcédoine : Ex canonum collectione quae dicitur Prisca (ACO, 2/2/1, p. 31-47) : titres et texte de 27 canons, suscriptions épiscopales, commentaire de certains canons

12. Chalcédoine : Ex collectione codicis Meermano-Westreeniani (ACO, 2/2/1, p. 99-109) : 27 canons

13. Chalcédoine : Concilium universale Chalcedonense. 5. Collectio Sangermanensis, 1936 (ACO, 2/5).

14. Chalcédoine : Ex collectione canonum Dionysiana aucta (ACO, 2/2/1, p. 61-95) : Definitio fidei, liste d'évêques, 26 canons

15. Chalcédoine : Ex collectione canon. Hispana (ACO, 2/2/1, p. 81-95) : Actio 6, 27 canons, édit impérial

16. Chalcédoine: Collectio Novariensis de re Eutychis (ACO, 2/2/1)

17. Chalcédoine: Rerum Chalcedonensium collectio Vaticana (ACO, 2/2/1)

18. Constantinople II : Actiones concilii (ACO, 4/2)

19. Constantinople II : Collectio codicis Parisini 1682 (ACO, 4/2, p. 101-184), 1 ms.

20. Constantinople II : Libelli de Jean Maxence (ACO, 4/2, p. 3-62), 1 ms. Libellus fidei - Capitula contra Nestorianos et Pelagianos - Professio brevissima catholicae fidei - Brevissima adunatio ratio verbi Dei ad propriam carnem - Responsio contra Acefalos - Dialogi contra Nestorianos libri II - Epistula Hormisae ad Possessorem - Responsio lohannis Maxentii.

21. Constantinople II : Collectio codicis Novariensis XXX (ACO, 4/2, p. 65-98), $1 \mathrm{~ms}$.

22. Constantinople II : Procli ad Armenos Tomus et epistule Johannis II (ACO, $4 / 2$, p. 196-210)

23. Latran (649): Secretaria (ACO, ser. 2/1)

24. Constantinople III : Concil. univ. Constantinopolitanum tertium. Actiones 1-18 (ACO, ser. 2/2) 
- Annexe $3:$ La Collectio Casinensis

A) ACO, 1/3 : Collectio Casinensis pars prior ou Synodicon de Rusticus, comprenant :

\section{p. 3 : Cyrille, Epistula ad monachos (Venerunt quidem) ;}

p. 16 : Cyrille, ${ }^{\text {re }}$ lettre à Nestorius (Viri reverendi et fide digni) ;

p. 17 : Nestorius à Cyrille ;

p. 17 : Cyrille, Ad eos qui eum accusaverunt ;

p. 18 : Contestatio Constantinopolitana ;

p. 20 : Cyrille, $2^{\mathrm{e}}$ lettre à Nestorius (Oblocuntur) ;

p. 23 : Nestorius à Cyrille (Iniurias) ;

p. 26 : Cyrille, $3^{\mathrm{e}}$ lettre à Nestorius (Salvatore nostro) avec anathèmes ;

p. 35 : Cyrille, Epistula ad Constantinopolitanos ;

p. 37 : Célestin, pape, à Nestorius ;

p. 37 : Célestin, pape, à Cyrille ;

p. 37 : Célestin, pape, au peuple et au clergé de Constantinople ;

p. 37 : Célestin, pape, à Jean d'Antioche (Tristitiae) ;

p. 38 : Cyrille à Acacius ;

p. 39 : Acacius à Cyrille ;

p. 40 : Cyrille à Jean d'Antioche (Cognovit omnino) ;

p. 41 : Cyrille à Juvénal ;

p. 43 : Cyrille ad quemdam zelotem;

p. 44 : Jean d'Antioche à Nestorius ;

p. 47 : Théodose et Valentinien, Sacra à Cyrille ;

p. 49 : Jean d'Antioche à Cyrille ;

p. 49 : Convocation du concile par Théodose et Valentinien ;

p. 51 : Théodose et Valentinien, Sacra ad concilium ;

p. 52 : [Prima actio] Gesta in sancta synodo Ephesena de recta fide (22 juin 431);

p. 82 : Condamnation de Nestorius ;

p. 83 : Seconde condamnation de Nestorius ;

p. 83 : Contre les opposants à la définition des 318 Pères de Nicée ; symbole avec monition aliam fidem... ;

p. 84 : Lettre aux clercs et économes de Constantinople ;

p. 84 : Cyrille au peuple d'Alexandrie ;

p. 85 : Relation aux empereurs de la condamnation de Nestorius ;

p. 87 : Cyrille à Comarius, Potamon, et al. ;

p. 89 : Cyrille aux moines ;

p. 90 : Commonitorium des évêques présents à Constantinople ;

p. 91 : Rescrit impérial ;

p. 92 : Secunda actio gestorum (10 juillet 431) ; 
p. 114 : Cyrille au clergé de Constantinople ;

...

p. 119 : [Tertia actio gestorum] (22 juillet 431) ;

p. 120 : Symbole de Nicée...;

p. 121-128 : Lecture de florilèges patristiques;

p. 129 : Charisii confessio fidei cum expositione eiusdem ;

p. 133 : Monition Aliam fidem...;

p. 133 : Extrait des écrits de Nestorius sur le dogme ;

p. 134 : Souscription des évêques participants ;

p. 140 : Lettres des évêques réunis à Constantinople à ceux du concile d'Éphèse ;

p. 143 : Relation au pape Célestin ;

p. 144 : Cyrille, Sermons prêchés à Éphèse ;

...

p. 145 : Cyrille, Contre Jean d'Antioche ;

.

p. 152 : Théodote d'Ancyre, Sermon I pour le jour de la Nativité du Sauveur ;

p. 161 : Théodote d'Ancyre, Sermon II pour le jour de la Nativité du Sauveur ;

...

p. 169 : Lettre-rapport du synode au pape Célestin ;

p. 173 : Lettre de mission du concile aux évêques envoyés à Constantinople ;

p. 174 : Relation adressée par le synode à l'empereur ; ...

p. 178 : Commonitorium adressé au clergé de Constantinople par le synode ;

p. 179 : Maximianus à Cyrille ;

p. 181 : Rescrit impérial contre Nestorius ;

p. 183 : Lettre des empereurs à Cyrille d'Alexandrie et Jean d'Antioche ;

p. 184 : Paul d'Émèse à Cyrille ;

p. 185 : Jean d'Antioche à Cyrille ;

p. 187 : Cyrille, Lettre à Jean d'Antioche (Exultent celi) ;

p. 191 : Sermon de Cyrille (23 avril 433) ;

p. 192 : Cyrille, Lettre à Maximianus (Non erat dubium) ;

p. 193: Commonitorium au prêtre Eulogius ;

p. 194 : Cyrille, Lettre à Acacius.

B) ACO, 1/4: Collectio Casinensis pars altera [env. 300 lettres] 
C) ACO, 2/3: Gestorum Chalcedonensium versio a Rustico edita :

p. 3-23: Concilium universale Chalcedonense. Epistularum ante gesta collectio [35 lettres] ;

p. 27-259: Concilium universale Chalcedonense. Actio prima ;

p. 263-561 : Gestorum Chalcedonensium versio a Rustico edita. Actiones 2-6; 7-16.

D) ACO, 2/4, p. 143-151, etc. : Leonis pape I epistularum [15] collectio.

Annexe 4 : Nombre de manuscrits des acta par siècle

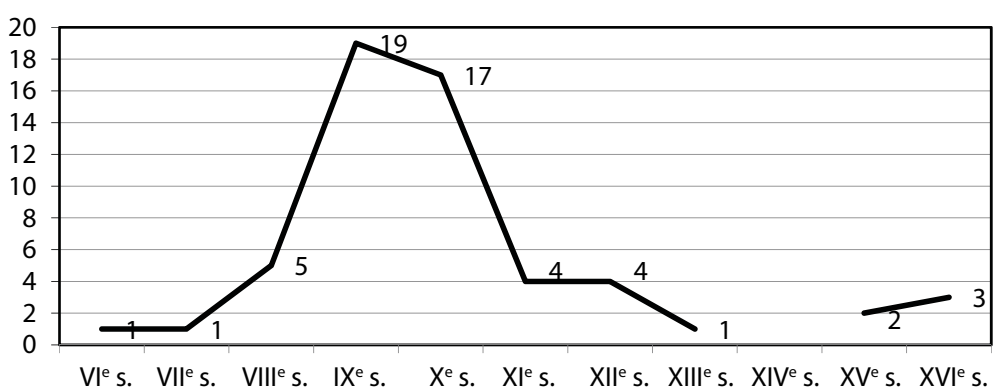





\section{La dramatique conciliaire de l'Antiquité à Vatican II}

Guillaume Cuchet, Charles Mériaux (dir.)

\section{Disponible en versions PDF et ePub}

sur le site des Presses universitaires du Septentrion

PDF - ISBN 978-2-7574-2816-0 : $26 €$

ePub - ISBN 978-2-7574-2825-2: $26 €$

Lot papier + numérique - ISBN 978-2-7574-2834-4 : $38 €$

\section{Retrouvez-nous}

sur www.septentrion.com

sur notre page Facebook

et sur Twitter

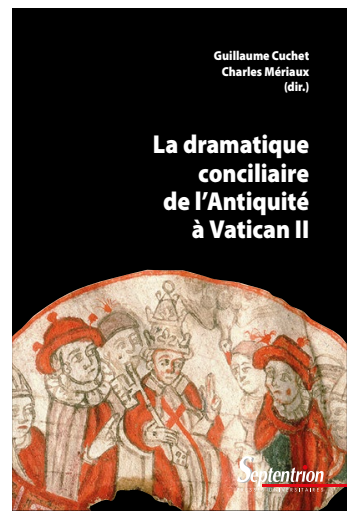




\section{Ouvrage composé par}

Émilie Duvinage

\section{Ouvrage réalisé avec}

La chaîne d'édition XML-TEI Métopes

Méthodes et outils pour l'édition structurée

avec la/les police(s) : Myriad Pro

\section{Dépôt légal}

septembre 2019

$1895^{\mathrm{e}}$ volume édité par

les Presses universitaires du Septentrion

59654 Villeneuve d'Ascq - France

\section{Septentrion}


Guillaume Cuchet est professeur d'histoire contemporaine à l'université Paris-Est Créteil. II travaille sur l'histoire et l'anthropologie religieuse des sociétés contemporaines.

Charles Mériaux est professeur d'histoire du Moyen Âge à l'université de Lille. II est spécialiste de I'histoire religieuse du haut Moyen Âge occidental.

Contributeurs Silvia Acerbi • Antoine Arjakovsky • Philippe Blaudeau • Séverine Blenner-Michel • Florence Close - Guillaume Cuchet • Davide Dainese • Thomas Deswarte • Pierre Antoine Fabre • Loïc Figoureux • Étienne Fouilloux - Étienne Lock • Catherine Masson • Sylvain Milbach • Hélène Millet • Nelson H. Minnich • Pascal Montaubin - Martin Morard • Jacques Prévotat • François-Xavier Romanacce • Émilie Rosenblieh • Philippe Roy-Lysencourt - Christian Sorrel • Ramón Teja • Sophie Vallery-Radot.

\section{La dramatique conciliaire de I'Antiquité à Vatican II}

En bonne théologie chrétienne, les conciles sont censés être «inspirés 》 ou «assistés » par le Saint-Esprit, mais force est de constater que leurs annales sont pleines de conflits, coups de théâtre, manœuvres, aussi bien dans la conduite des assemblées que la rédaction des documents qui en sont issus. Vues de près, les opérations du Saint-Esprit paraissent bien humaines. Cet ouvrage étudie, dans la longue durée et à des échelles différentes, les ressorts historiques de cette «dramatique conciliaire ». Comment comprendre que les acteurs des conciles aient pu être à la fois des tacticiens rompus aux usages de la mécanique des assemblées et des croyants sincères, convaincus que le Saint-Esprit pilotait en sous-main les opérations et que ce combat en apparence politique était en réalité spirituel ? Qu'est-ce que ces convictions nous disent de la nature de ces assemblées si particulières que sont les conciles?

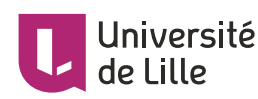
de Lille

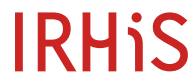

Institut de Recherches
Historiques du Septentrion

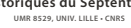

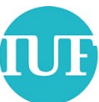

institut universitaire de France
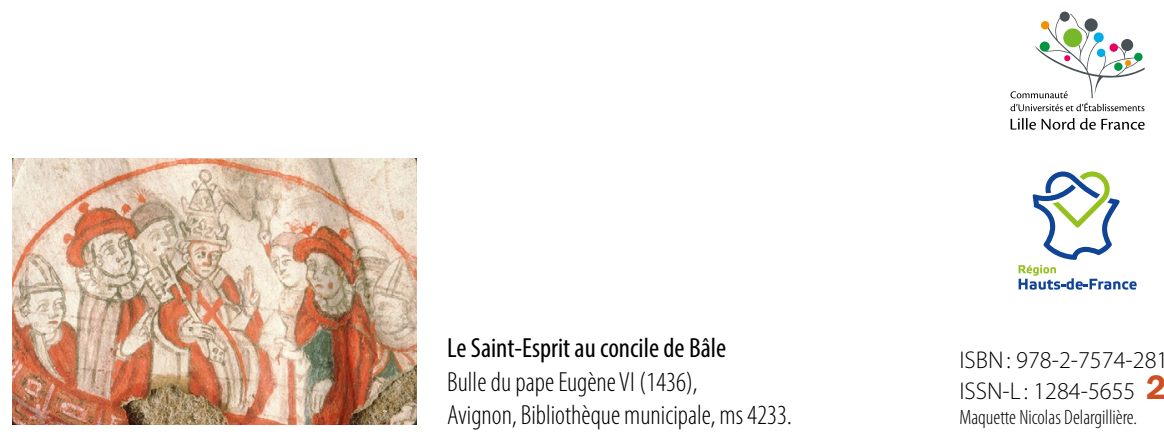

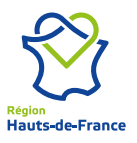

